DOE/EV-0008/1

The Multistate Atmospheric Power Production Pollution Study

Program Plan
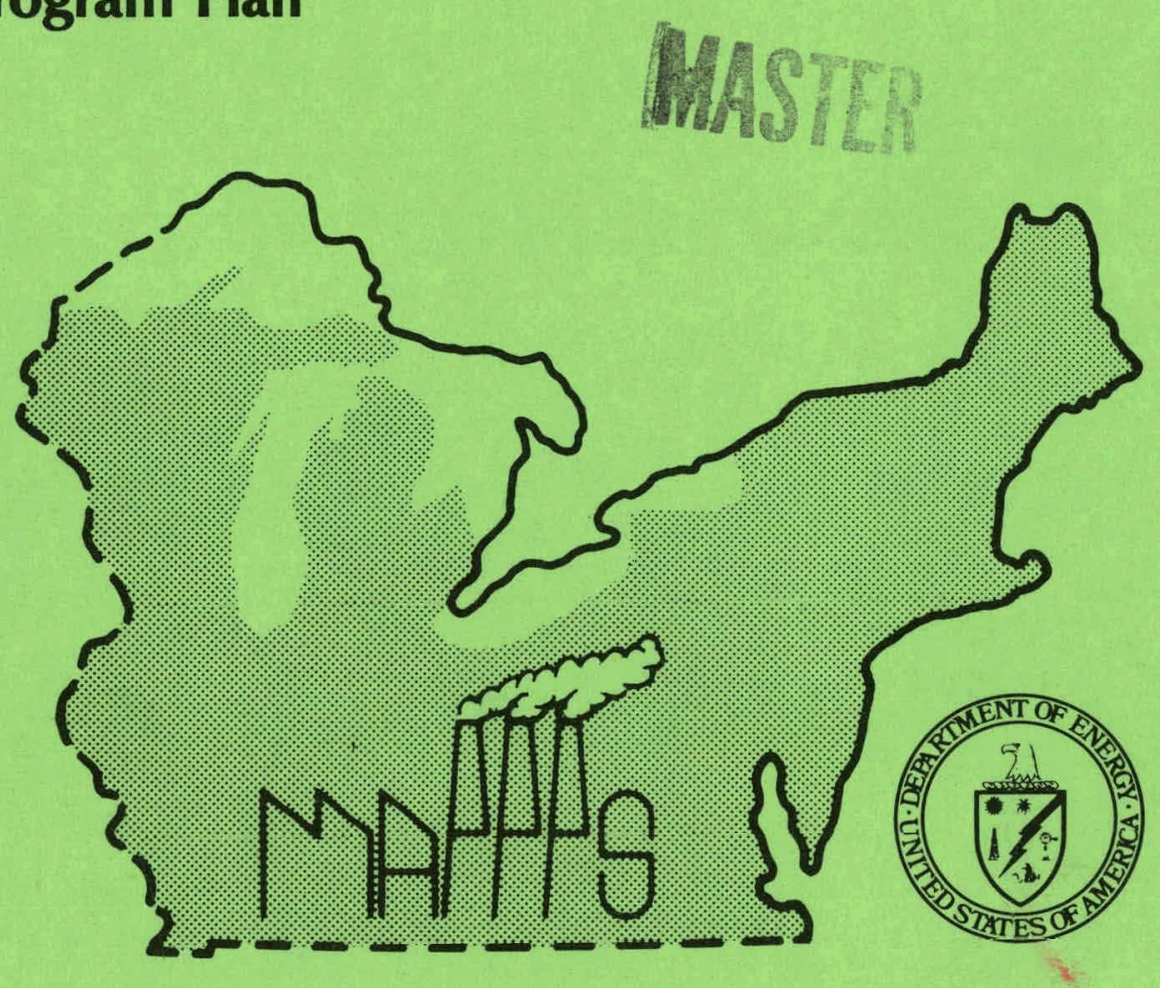

Sponsored by;

$\checkmark$ U.S. Department of Energy

Assistant Secretary for Environment

Division of Biomedical and

Environmental Research

January 1978 


\section{DISCLAIMER}

This report was prepared as an account of work sponsored by an agency of the United States Government. Neither the United States Government nor any agency Thereof, nor any of their employees, makes any warranty, express or implied, or assumes any legal liability or responsibility for the accuracy, completeness, or usefulness of any information, apparatus, product, or process disclosed, or represents that its use would not infringe privately owned rights. Reference herein to any specific commercial product, process, or service by trade name, trademark, manufacturer, or otherwise does not necessarily constitute or imply its endorsement, recommendation, or favoring by the United States Government or any agency thereof. The views and opinions of authors expressed herein do not necessarily state or reflect those of the United States Government or any agency thereof. 


\section{DISCLAIMER}

Portions of this document may be illegible in electronic image products. Images are produced from the best available original document. 


\title{
MAP3S*: STUDYING THE TRANSPORT, TRANSFORMATION, AND FATE OF ATMOSPHERIC ENERGY-RELATED POLLUTANTS
}

\author{
Michael C. MacCracken
}

October 1977

This report was prepared as an account of work
sponsored by the United States Govemment. Neither the
United States nor the United States Department of
Energy, nor any of their employees, nor any of their
contractors, subcontractors, or their employees, makes
any warranty, express or implied, or assumes any legal
liability or responsibility for the accuracy, completeness
or usefulness of any information, apparatus, product or
process disclosed, or represents that its use would not
intringe prtvately owned rignts.

*Multistate Atmospheric Power Production Pollution Study (MAP3S) 


\section{NOT ICE}

This report was prepared as an account of work sponsored by the United States Government. Neither the United States nor the United States Department of Energy, nor any of their employees, nor any of thnie onntruntorn, muhnntrantnrn, $\mathrm{nF}$ thoir emplovege. makes any warranty, express or implied, or assumes any legal liability or responsibility for the accuracy, completeness or usefulness of any information, apparatus, product or process disclosed, or represents that its use would not infringe privately owned rights.

Available from:

National Technical Information Service (NTIS) U.S. Department of Commerce

5285 Port Royal Road șpingfield, Virginia 22161

Price: $\quad$ Printed Copy: $\quad \$ 6.00$

Microfiche: $\quad \$ 3.00$ 


\section{FOREWORD}

The President, in outlining the National Energy Plan, 1977, recommended the increased use of coal to meet increasing needs for national energy and to reduce the U.S. dependence on imported petroleum. Also, the President stated that coal consumption should be increased in a manner consistent with existing national commitments to protect and improve the environment. Following the Arab oil embargo in 1973-74, the Congress passed the Energy Supply and Environmental Coordination Act of 1974 (ESECA). ESECA was enacted to give the Federal Energy Administration (FEA) the authority to order certain oil and gas burning utilities and industries to convert their steam boilers to coal and, at the same time, comply with Federal and State air quality regulations. The 1977 Amendments to the Clean Air Act contain a regulation for the Prevention of Significant Deterioration, which requires that all States must designate all regions into one of three classes:

Class I (no further degradation of existing clean air).

Class II . (some degradation permitted).

Class III [degradation permitted but not to exceed secondary National Ambient Air Quality Standards (NAAQS)].

In addition, all International Parks, National Wilderness Areas greater than 5000 acres in size, and all National Parks in existence as of August 3, 1977, are designated Class I areas. Most states are currently designated as Class II areas subject to future reclassification by state and local actions. Maintenance of existing visibility is considered an important value in Class $I$ areas.

The assessment of coal usage strategies resulting from the National Energy Plan and ESECA actions and the impact of these strategies on air quality, as established and amended by the Clean Air Act, requires the capability to predict long-range transport and removal processes that control the fate of fossil-fuel combustion emissions.

Accordingly, the Division of Biomedical and Environmental Research (DBER), Assistant Secretary for Environment (ASEV), is sponsoring a major research program called the Multistate Atmospheric Power Production Pollution Study (MAP3S). The ubjective of the program is to develop and demonstrate an improved, verificd capability to numerically simulate the present and future changes in pollutant concentration, atmospheric behavior, and precipitation chemistry resulting from pollutant releases to the atmosphere from power production processes, primarily coal. Development of the numerical modeling capability needed for accurate and reliable air quality predictions, assessment of human health, and biological implications, requires an understanding of the source, transport, transformation, and removal processes affecting nonregulated pollutants as well as criteria pollutants. To achieve this understanding, an integrated program of pollutant characterization, field experiments, and numerical modeling has been started for the populous, energy-intensive, northeast quadrant of the United States. 
Field measurement programs have been initiated within the MAP3S research region to:

- Increase the frequency of surface observations of a wide spectrum of pollutants, in cooperation with the EPRI-Sulfur Regional Experiment (SURE) project.

- Provide vertical and horizontal cross sections of pollutant concentrations.

- Determine the physical-chemical properties of sulfate and associated aerosols.

- Provide regional atmospheric turbidity data.

- Determine the temporal and spatial distribution of acidic precipitation and the chemical composition of precipitation.

Meteorological ficld cxperiments will improve on the existing capability to treat boundary layer dynamics, flow fields and diffusion in complex terrain, dry dcposition, preoipitation ecavenging, and (by the use of inert shemical tracers) transport on scales of hundreds of kilometers.

Improved numerical models, relating temporal and spatial pollutant distributions and concentrations to current and planned source distributions and intensities, will increase the credibility and value of the many assessment studies under way in MAP3S. The data sets generated in MAP3S for model verification will be equally valuable in studies of health and ecological effects. For example, the precipitation chemistry data base is needed to estimate the effects of power production emissions on the chemistry and biological activity in lakes.

A strong interaction with the ASEV National Coal Utilization Assessment program and related regional studies is encouraged. Also, the dissemination of MAP3S data and models to potential users is being pursued through newsletters, meeting presentations and seminars, and this research plan with its accompanying project reports (FY-1977 Addendum and annual updates). Coordination with EPA's planned STATE program is also anticipated.

Jeff Swinebroad

Program Manager

Environmental Programs 


\section{CONTENTS}

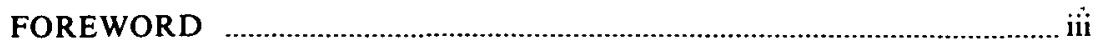

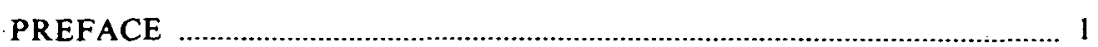

1. EXECUTIVE SUMMARY ………...................................................... 3

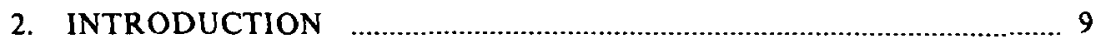

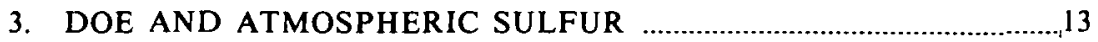

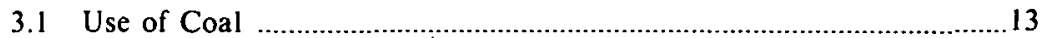

3.2 Environmental Effects of Coal Usage …...........................................13

3.3 Relationship of MAP3S to Regulatory Actions ……........................14

3.4 Status of Research in Fossil-Fuel Emissions …..................................14

3.5 Sulfur Oxides and Other Pollutants ..............................................15

3.6 Expertise in the DOE National Laboratories ……………...............16

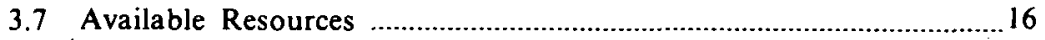

4. MAP3S SCIENTIFIC PROGRAM - RESPONDING TO

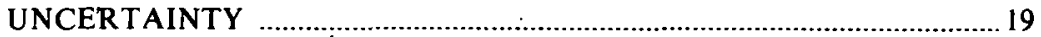

4.1 MAP3S Research Tasks ……………………………………… 20

Task 1 - Power Production Emissions ……………..........................22

Task 2 - Nonpower Production Emissions ....................................... 23

Task 3 - Pollutant Properties :.................................................... 24

Task 4 - Pollutant Distribution …….......................................... 25

Task 5 - Pollutant Transport ………………………………....... 26

Task 6 - Pollutant Transformation ................................................ 31

Task 7 - Surface Removal Processes ............................................. 34

Task 8 - Pollutants and Precipitation ............................................. 35

Task 9 - Weather and Climate Modification … .......................... 38

Task 10 - Numerical Modeling and Analysis .............................. 40

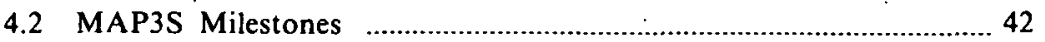

5. MAP3S PROGRAM MANAGEMENT ……………………................. 47

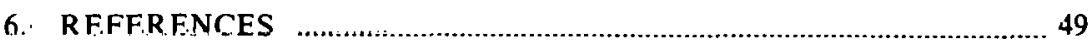

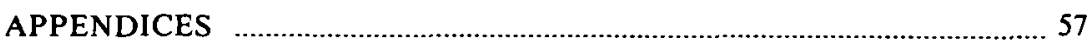

A - Agency and Program Abbreviations …………………............5 57

B - MAP3S Budget .................................................................. 59

C - MAP3S Research Accomplishments ………………………........61 63

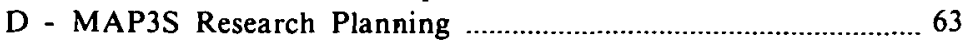

E - MAP3S Management Structure ……………………...................65

F . DOE MAP3S-Related Healli-Effects Research ......................67

G - DOE MAP3S-Related Ecology-Effects Research ..................... 71 


\title{
PREFACE
}

The Multistate Atmospheric Power Production Pollution Study (MAP3S) was first suggested by Mr. David Slade, now Deputy Manager of Environmental Programs, Division of Biomedical and Environmental Research, DOE*. Building on the results of the productive Chemist/Meteorologist Workshop $†$ held in January 1975, representatives from the then ERDA national laboratories (particularly, Dr. Paul Frenzen of ANL, Dr. Paul Michael of BNL, and Dr. Charles Elderkin of PNL) and contract research groups (particularly, Mr. Richard Semonin of ISWS) outlined the needed research and program tasks for MAP3S.

The MAP3S program was not officially initiated until FY-1977 (October 1, 1976); however, in early FY-1976, several national laboratories began focusing on research activities that were directed toward the program's goals. We have used the experience from those activities in preparing this planning document.

The development of this plan has benefited greatly from individuals now active in atmospheric research at the national laboratories, especially:

Argonne National Laboratory

Dr. Paul Frenzen

Mr. Brucc Ilicks

Dr. Paul Cunningham

(Battelle) Pacific Northwest Laboratory

Dr. Jeremy Hales

Dr. Larry Wendell

Brookhaven National Laboratory

Dr. Paul Michael

Dr. Leonard Newman

Mr. Ronald Meyers

Dr. Steven Schwartz

Other organizations, university groups, individual scientists, and a number of independent reviewers, have also contributed to the evolution of the original research suggestions in this working plan.

To a large extent, this plan was prepared before the International Symposium on Sulfur in the Atmosphere (of which DOE was a cosponsor) took place. However, the-scientific progress reported at the symposium and formulated in workshnp meetings will serve as an important source in the continuing evolution of MAP3S.

\author{
Michael C. MacCracken \\ MAP3S Project Director \\ Lawrence Livermore Labơratory
}

\footnotetext{
* Abbreviations used in this report are listed in Appendix A.

$\dagger$ Slade, Beadle, and Newell, 1975.
} 


\section{THIS PAGE}

\section{WAS INTENTIONALLY}

\section{LEFT BLANK}




\section{EXECUTIVE SUMMARY}

The goal of the Multistate Atmospheric Power Production Pollution Study (MAP3S), a major DOE research program, is to develop and demonstrate an improved, verified capability of numerically simulating the present conditions and potential changes in pollutant concentration, atmospheric behavior, and precipitation chemistry that result, or will result, from pollutants released to the atmosphere by large-scale power production processes (primarily those that use coal combustion).

Results from the MAP3S program will form the basis for answering two critical questions relating to energy and environmental planning:

- Will precipitation acidity and atmospheric turbidity in the United States increase as coal combustion increases?

- Can atmospheric concentrations of particulate sulfur be reduced by decreasing sulfur oxide emissions?

The MAP3S program : was largely motivated by the necessity of providing agencies (charged with meeting the nation's energy needs) with the knowledge required to assess options for generating power with minimal damage to human health and the natural environment.

Coal is the most abundant resource of domestic fossil energy; also, electric power production is a major and growing part of our energy economy. Consequently, MAP3S focuses on the effects of emissions from coal-fired electric power plants in the context of emissions from all other sources with which they interact. The area of study is the high-population, energy-intensive, northeastern quadrant of the United States.* Improved numerical models, resulting from the study, will be made available for use in regional studies and assessments.

The MAP3S program is charged with studying the entire spectrum of atmospheric pollutants ascribed to fossil-fuel electric power production or that may interact in the atmosphere with power plant emissions. These pollutants include:

- Sulfur oxides, sulfites, and șulfates.

- Nitrogen oxides and their secondary reaction products, including oxidants.

- Hydrocarbons, including polycyclic organic matter.

- Trace inorganic elements.

- Particulates, which may contain any or all of the above substances and elemental carbon or soot.

*This region, referred to as the Greater Northeast, includes the upper Midwest, the Northeast, and areas directly influencing air quality in the region. 
Numerical modeling capability is needed to accurately assess the human health and biological implications (e.g., dose-to-man and dose-to-ecosystems) of this complex and interacting set of pollutants. Its development requires an understanding of the natural and anthropogenic sources and the transport, transformation, and removal processes affecting the pollutants. As a result, the MAP3S program is divided into three closely coupled subprograms: characterization, field experiments, and numerical modeling. Within these subprograms, the needed research is categorized by 10 interrelated program elements, or tasks. Each task concentrates on an area of significant scientific uncertainty. Summarized briefly, the tasks are:

1. To specify and quantify the emissions of atmospheric energy-related (AER) pollutants from present power production plants, and to consider pollutants that may be emitted as a result of an increased usage of coal and the introduction of new power production processes, e.g., fluidized bed combustion and magneto hydrodynamic (MHD) systems.

2. To identify and quantify sources of pollutants that do not stem directly from power production but that may affect the concentration, distribution, uansfurmatiun, and fate of $\Lambda \mathrm{ER}$ pollutants.

3. To characterize the physical and chemical properties of AER pollutants commonly found in the atmosphere on a regional scale. These properties include particle size, oxidation state, derivative compounds, molecular form, etc.

4. To determine the spatial and temporal distribution of AER pollutants under both average and extreme conditions.

5. To determine the processes and parameters governing the vertical and horizontal transport of AER pollutants.

6. To identify the chemical and physical transformation processes affecting AER pollutants, and to determine the rates and mechanisms controlling such processes.

7. To determine the rates of physical and biochemical mechanisms governing the removal of AER pollutants from the atmosphere at the earth's surface (dry deposition').

8. To identify the mechanisms and rates governing the removal of AER pollutants by precipitation scavenging, and to determine the effects of $\Lambda E R$ pollutants on trace material balances and precipitation chemistry, specifically the acid-base relationships.

9. To determine the effects of AER pollutants on weather and climate, including effects on visibility, radiation transport, and on the amount and extent of precipitation.

10. To develop, verify, and demonstrate methods (numerical models) that will make it possible to accuratcly simulate the atmospheric transport and transformatinn of AER pollutants. for use in assessing various strategies for generating power. 
The initial priority, during the current three-year phase of the MAP3S program, is to study sulfur oxides, sulfates, and their associated cations. The reasons for this priority are:

- Sulfur oxides are major pollutants that stem from the combustion of coal - our most abundant, short-term energy resource. Further, we expect the use of coal to increase substantially as the nation strives to reduce its dependence on foreign oil.

- Potential environmental and human health consequences of AER pollutants have been of interest for many years. Although uncertainty exists, a major attributive factor may be the sulfur oxides and their oxyacids and salts.

- The setting of an air quality standard for particulate sulfur appears likely within several years (EPA, 1975). But the health research will probably be inadequate to justify standards for the other pollutants until the 1980's (Bachman, 1976). The implementation of an adequate and effective control strategy will require an understanding, rather than simple parameterization, of the atmospheric sulfur cycle.

- Research on atmospheric sulfur oxide/sulfate pollutants is ongoing or planned by other agencies of the Federal Government, by foreign governments, and by the electric power industry. Efforts by DOE can substantially contribute to progress in this field, and we will coordinate our studies with the work of these other organizations.

- Many technical advances needed to deal with sulfur oxides/sulfates will be directly applicable for dealing with the other pollutants noted. Examples include sampling methods, modeling of atmospheric chemistry, and understanding flow patterns in complex terrain.

- Considerable expertise in atmospheric physics and sulfur-compound chemistry is available within DOE national laboratories and within contractor groups that DOE/ERDA has supported in recent years. Also, by working logether, the laboratories provide a strong coupling between field experiments and numerical modeling.

- Given budgetary constraints, more significant advances may be achieved by focusing on a single category of pollutants, instead of diluting the available research by focusing on several categories at once.

In adopting this special priority for sulfur oxides, we recognize growing evidence that the fate of sulfur oxides cannot be completely separated from the fate of other pollutants. For example, nitrogen oxides appear to play an important role in controlling both precipitation acidity and atmospheric oxidant concentrations. Therefore, in establishing this priority, we intend only to identify a central pollutant (as opposed to oxidants or nitrogen oxides) and not an exclusive pollutant of interest.

MAP3S participating groups will concentrate their research on project elements that will clarify our understanding of the atmosphere's effect on pollutants and that will integrate with major ongoing and proposed programs of EPRI, EPA, and other organizations. This focus and coordination will enable us to gain a comprehensive understanding of how coal can be used to meet the nation's energy needs with a minimum impact on human health and the environment. 
The present direction of the MAP3S program, which is still evolving, is summarized in Table 1. In some cases, only the major participants are identified. The background and rationale on which the program is based are described in the body of this report. The next three years (FY-1977 through 79) will serve as the major research period for developing the capability to numerically simulate the atmospheric behavior, concentration, and chemistry of the sulfur species. The total core budget for FY-1977 is approximately \$3 million. Detailed budget breakdowns are given in Appendix B. Present and planned MAP3S research activities are described briefly in Appendices $C$ and $D$, respectively. The structure for managing the MAP3S program is outlined in Appendix E.

By design, MAP3S is restricted to the study of atmospheric phenomena. But its results are tailored for broad use by other research programs, within DOE and in government agencies, to characterize pollutant surces, to contrul pullutalit emissions, and to assess pollutant effects on human health (Appendix F) and ecology (Appendix $G$ ). The full value of MAP3S lies in communicating program findings to the research community concerned with the health and environmental effects of the atmospheric pollutants studied under MAP3S. Accordingly, our development of the mechanisms to distribute and coordinate program findings as they evolve is integral to MAP3S. 


\section{Table 1}

\section{CURRENT DIRECTION OF RESEARCH STUDIES BY MAP3S PARTICIPANTS}

\begin{tabular}{|c|c|c|c|}
\hline & Task & Research response & Research groups \\
\hline 1. & $\begin{array}{l}\text { Quantify emissions } \\
\text { from power produc- } \\
\text { tion sources }\end{array}$ & $\begin{array}{l}\text { Measure power-plant plumes } \\
\text { Compile emission inventories }\end{array}$ & $\begin{array}{l}\text { BNL } \\
\text { BNL }\end{array}$ \\
\hline 2. & $\begin{array}{l}\text { Quantify emissions } \\
\text { from nonpower } \\
\text { production sources }\end{array}$ & Compile emission inventories & BNL \\
\hline 3. & $\begin{array}{l}\text { Characterize pollu- } \\
\text { tant properties }\end{array}$ & $\begin{array}{l}\text { Determine aerosol composition } \\
\text { Improve measurement and analysis } \\
\text { capabilities }\end{array}$ & $\begin{array}{c}\text { ANL, BNL, BYU, LBL, } \\
\text { PNL** }\end{array}$ \\
\hline 4. & $\begin{array}{l}\text { Determine pollutant } \\
\text { distribution }\end{array}$ & $\begin{array}{l}\text { Acquire network data, including } \\
\text { SURE data } \\
\text { Sample pollutants, using special } \\
\text { instruments } \\
\text { Conduct aircraft sampling } \\
\text { Evaluate network quality }\end{array}$ & $\begin{array}{l}\text { BNL } \\
\text { ANL, BNL } \\
\text { BNL, PNL } \\
\text { EML }\end{array}$ \\
\hline 5. & $\begin{array}{l}\text { Determine pollutant } \\
\text { transport }\end{array}$ & $\begin{array}{l}\text { Conduct inert-tracer studies } \\
\text { Determine vertical spreading, } \\
\text { inversion formation, and decay } \\
\text { Verify wind field models }\end{array}$ & 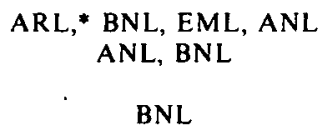 \\
\hline 6. & $\begin{array}{l}\text { Identify pollutant } \\
\text { transformation } \\
\text { mechanisms }\end{array}$ & $\begin{array}{l}\text { Study point-source plumes } \\
\text { Study urban-source plumes } \\
\text { Study oxygen isotopes } \\
\text { Study box budgets and episodes }\end{array}$ & $\begin{array}{c}\text { BNL, PNL* } \\
\text { PNL } \\
\text { ANL } \\
\text { ANL, BNL, PNL }\end{array}$ \\
\hline 7. & $\begin{array}{l}\text { Determine mechanisms } \\
\text { governing pollutant } \\
\text { removal at the surface }\end{array}$ & Study dry deposition & ANL, ${ }^{*}$ PNL \\
\hline 8. & $\begin{array}{l}\text { Identify mechanisms } \\
\text { of pollutant } \\
\text { scavenging by, and } \\
\text { effect on, } \\
\text { precipitation }\end{array}$ & $\begin{array}{l}\text { Perform field experiments in cloud } \\
\text { systems } \\
\text { Conduct numerical modeling } \\
\text { Operate mesoscale precipitation } \\
\text { and chemistry network } \\
\text { Operate multistate precipitation } \\
\text { chemistry network } \\
\text { Model precipitation mechanism } \\
\text { Analyze ME T KUMEX precipitation } \\
\text { chemistry data }\end{array}$ & $\begin{array}{c}\text { PNL } \\
\text { PNL, BNL, ISWS* } \\
\text { ISWS* } \\
\text { PNL, university groups* } \\
\text { PNL } \\
\text { ISWS* }\end{array}$ \\
\hline 9. & $\begin{array}{l}\text { Determine pollutant } \\
\text { effects on weather } \\
\text { and climate }\end{array}$ & Develop a turbidity network & ANL \\
\hline 10. & $\begin{array}{l}\text { Develop numerica! } \\
\text { modeling for } \\
\text { assessment }\end{array}$ & $\begin{array}{l}\text { Develop plume models } \\
\text { Develop trajectory models } \\
\text { Develop regional models } \\
\text { Conśtruet data bank }\end{array}$ & $\begin{array}{l}\text { BNL, PNL** } \\
\text { PNL, ARL,* ANL, BNL } \\
\text { BNL, ANL } \\
\text { BNL }\end{array}$ \\
\hline
\end{tabular}

* MAP3S participant carries out projects with at lẹast partial funding from other organizations (e.g., EPRL. EPA, and NSF). 


\section{THIS PAGE}

\section{WAS INTENTIONALLY LEFT BLANK}




\section{INTRODUCTION}

In recent years, the national desire to improve environmental quality has resulted in a number of emission control programs (and proposals for others). These programs seek to resolve many of the important problems in atmospheric pollution. It has been recognized that strategies for diminishing pollution on a local scale $(<100 \mathrm{~km})$ have not been entirely successful with respect to secondary pollutants (e.g., sulfates and oxidants) and species with long atmospheric residence times (e.g., aerosols). Consequently, the possible effects of the long-range transport of pollutants on regional (interstate) and continental scales (e.g., see Slade et al., 1975; OECD, 1977) have become of increasing interest. This situation has been accentuated because it is coupled to the emerging conflict between the twin national goals of energy self-sufficiency and preservation of environmental quality.

The technological and resource aspects of available options for generating electric power in the next decade point to the increased use of fossil fuels, particularly coal. The use of fossil fuels, however, leads to the emission of sulfur and nitrogen oxides, along with minor amounts of hydrocarbons, elemental carbon, and trace inorganic elements. These emissions may occur as gases or particles and, often, they involve complex chemical combinations of such compounds. Atmospheric reactions between these compounds and similar emissions from other sources may also lead to secondary pollutants, including oxidants. Alternatively, photochemical pollution caused by nonpower plant emissions may accelerate the conversion of emissions from power plants to more harmful compounds.

The fractional share of some pollutants contributed by electric power plants is now quite high [e.g., EPA (1976) calculates that coal-fired power plants contribute $55 \%$ of the nation's $\mathrm{SO}_{2}$ emissions]. Unless strong controls are implemented, emissions of AER pollutants can be expected to increase, as more power plants come into operation and reliance is placed on high-sulfur coals. Thus, one objective of the MAP3S program is to identify how various control strategies (e.g., reducing $\mathrm{SO}_{2}$ emissions, limiting nonpower plant hydrocarbons and nitrogen oxide emissions) will compare in their effectiveness to reduce sulfur oxide particulate concentrations.

The MAP3S program will focus on understanding the relationship of emissions to pollutant concentrations at pollutant levels that have been correlated with, and to a limited extent causally related to, a wide range of detrimental effects. Particularly important are the adverse effects on human health and welfare and the biological environment, the deterioration of atmospheric visibility, the acidification of precipitation, and the damage to building structures and materials. In this country, current assessiments of these ettects have focused on the Greater Northeast (e.g., NRC, 1975), where the highest levels of such pollutants.as sulfates are observed. Recent research has even more clearly highlighted concerns related to the 
acidification of precipitation (Likens and Bormann, 1974; Likens, 1976; Odén, 1976) and the reduction of sunlight (Robinson, 1962; Dyer and Hicks, 1965; Wesely and Lipschutz, 1976; Bolin and Charlson, 1976). Abroad, studies have shown similar effects on the acidification of precipitation in Scandinavia and northeastern Europe (e.g., Bolin et al., 1971; Ottar, 1976; Prahm et al., 1976). Also, we cannot rule out the possibility that pollution from North America impacts northern Europe (Nyberg, 1976).

The relative severity of these atmospheric effects under both average and extreme conditions is uncertain. Also, the biological and economic consequences of the effects are not easy to quantify in a manner comparable to the direct capital and operational costs of emission control devices. Nonetheless, observed adverse effects correlate with increased concentrations of pollutants (particularly, atmospheric sulfur compounds) that are associated with the cxpccted increase in fossil-fuel consumotion. This correlation, although preliminary, clearly indicates that we need a major national effort to improve the understanding of such effects and to facilitate the development of a rational, responsive control program.

The National Coal Utilization Assessment (NCUA), ${ }^{*}$ a companion project within ASEV, is now providing short-term support in determining pulicy concerning the expanding role of coal as a future energy resource. This program is using the best available information and analysis techniques. Figure 1 is indicative of the results obtained in this assessment, using current, state-of-the-art modeling capabilities. However, both the magnitude and the distributions of the concentrations shown in the figure can be changed dramatically by altering the modeling assumptions. The degree of verisimilitude attained in today's regional air quality models is usually realized by "tuning" the particular assumptions used in the models (e.g., deposition and transformation rates, mixing heights, etc.). Truly useful diagnostic models, however, will require more accurate representations of the important physical and chemical processes. This will allow a firmer foundation of atmospheric chemistry and physics, on which to base future commitments to expend many billions of dollars on control equipment and on the continuing energy and maintenance costs to operate it. $\dagger$

To provide the necessary scientific knowledge and to improve the capability to determine the effects of energy-related emissions, DOE's Division of Biomedical and Environmental Research (DBER) is developing and implementing a broad research program that addresses the environmental and econometric effects associated with each step of the fuel cycle. The present MAP3S plan focuses on the atmospheric aspects of the DBER program; its first phase emphasizes sulfur compounds that result mainly from coal combustion. In planning the research activities, we are concentrating on the needs of health and ecology research programs, particularly those sponsored by ASEV. The output of the atmospheric models will then be in the proper framework for evaluating such factors as dose-toman and dose-to-ecosystems (see Appendices F and G).

\footnotetext{
* The project is managed by $\dot{\mathrm{r}}$. J. Hoover (ANL). See the NCUA project plan (ERDA, 1977) fur furtilıes details and Renne (1976) for a summary of the modeling capabilities being used in NCUA.

†The NRC report.(1975) indicates that the capital cost of the flue-gas desulfurization control devices will bc about \$100 million for a 1000-MWe power plant. Operational costs would be additional. Also, se. Jimesun (1975).
} 
The intent of this report is to provide both a perspective of the sulfate problem and a guiding plan for MAP3S as the program moves from a preliminary, largely organization year (FY-1976) into the first of at least three years (FY-1977 to 79) of major field work and modeling. We will use regular reviews to keep this plan current.

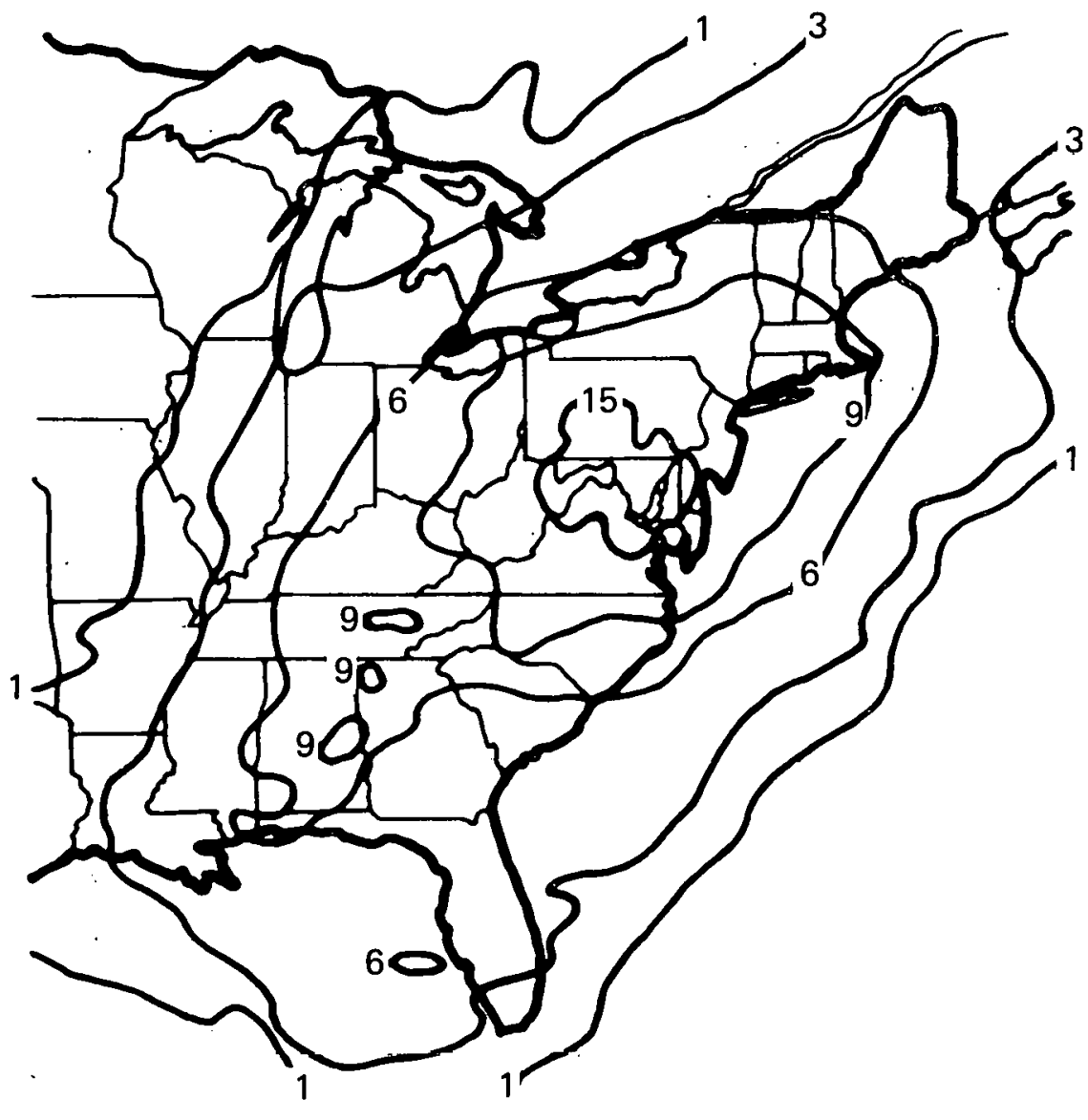

FIGURE 1 - Mean surface concentration $\left(\mu \mathrm{g} / \mathrm{m}^{3}\right)$ of sulfate $\left(\mathrm{SO}_{4}\right)$ from trajectory model calculation, involving $\mathbf{7 4}$ point sources (which account for about one-third of the $\mathrm{SO}_{2}$ emissions in the region shown), winds at 12-hr intervals for October 1974, uniform vertical mixing over $1000 \mathrm{~m}$ in depth, in-stack conversion of $2 \%$. conversion rate of $\mathrm{SO}_{2}$ to $\mathrm{SO}_{4}$ of $5 \% / \mathrm{hr}$, and deposition velocities for $\mathrm{SO}_{2}$ and $\mathrm{SO}_{4}$ of 3 and $0.3 \mathrm{~cm} / \mathrm{sec}$, respectively (Meyers and Cederwall, 1975). Despite the relatively crude physics and chemistry, the model results generally reflect the observed pattern and level of atmospheric sulfate in the Greater Northeast. 
THIS PAGE

WAS INTENTIONALLY LEFT BLANK 


\section{DOE AND ATMOSPHERIC SULFUR}

As part of its biomedical and environmental responsibilities, DOE is interested in the fate and effects of contaminants resulting from current and proposed power production processes. DOE is particularly interested in improving the understanding of the emission, transport, transformation, and fate of pollutants resulting from the combustion of fossil fuels, because these fuels are the nation's primary energy resource. Consequently, we discuss coal and its combustion pollutants within the context of today's research and the MAP3S program, whose first phase will focus on sulfur compounds, particularly those resulting from the combustion of coal. Because of the interactive role other pollutants play, however, this focus on sulfur is not meant to exclude the complex, and sometimes indirect, interactions occurring among sulfur oxides, nitrogen oxides, and photochemical oxidants.

\subsection{USE OF COAL}

The electric power industry is the major consumer of coal in this country. It uses about $70 \%$ of the total coal produced today. Before the 1973 oil embargo, U.S. utilities began shifting to petroleum-based fuels because of economic considerations, availability, and the necessity to meet air quality standards. This major shift has been largely halted by escalating petroleum prices and the recognition that the nation must depend less on foreign oil. In the near term, this implies a greater use of coal, our most abundant and technologically available energy resource, in electric power generation and as a source of synthetic fuels.

\subsection{ENVIRONMENTAL EFFECTS OF COAL USAGE}

The mining, transportation, and storage of coal give rise to a variety of environmental concerns. But the direct combustion of coal for electric power production and industrial/commercial purposes produces large quantities of gaseous and particulate waste products that enter the atmosphere. For example, major coal users (not just power plants) produce about two-thirds of the total national emissions of $\mathrm{SO}_{2}$ (EPA, 1975). These emissions, by virtue of their conventional disposal through large volume stacks, enter the atmosphere and, eventually, terrestrial and aquatic environments. Moreover, through direct or complex pathways, these emissions can eventually affect human health and welfare.

The effects of atmospheric pollutants on human health have received considerable attention in the CHESS studies (EPA, 1974), although the validity of such effects has been the subject of a detailed Congressional report (Committee on Science and Technology, 1976). Much uncertainty on the topic still exists, and the need for further research is clear (Comar and Nelson, 1975; OTA, 1976; Colucci, 1976; Lipfert, 1977). Prcliminary studies indicate, however, that the concentrations of atmospheric particulate-sulfur compounds, often observed in the northeastern United States and especially in urban areas, can be an important health parameter (Coffin and Knelson, 1976). 
Effects of atmospheric pollution on the environment may be more severe than they are on man. The effects of sulfur oxides on precipitation chemistry have been extensively documented in Europe (e.g., Braekke, 1976). Also, growing concern has been expressed in the United States. Likens (1976) and Likens and Bormann (1974) cite studies that show increased acidity at the Hubbard Brook Experimental Forest in New Hampshire. Their summarized data also indicate that average annual acidity over much of the northeastern United States has an acidity $(\mathrm{pH})$ near 4 and that, on occasion, pH values as low as 2.1 have been observed (Fisher et al., 1968). Ecological impacts of such acid precipitation can be significant. Acid precipitation can affect fish (Braekke, 1976), plant reproduction (Evans and Bozzone, 1976), crop yield (Hindawi et al., 1977), and plant growth and soil deterioration (ICEAP, 1976; FISAPFE, 1976). Effects on aquatic ecosystems are intensified when melting occurs in the spring. because of the long winter build-up of sulfur oxides and particulates in snow (Tempelmeyer, 1974).

The sulfur budget plays a major role in modifying precipitation chemistry, and the part that electric power production plays in the sulfur budget reinforces the urgency, raised by potential health and ecological effects, for a more complete assessment of the potential impact of the increased use of coal on atmospheric processes and properties.

\subsection{RELATIONSHIP OF MAP3S TO REGULATORY ACTIONS}

The undertaking of the MAP3S research program is not intended to delay regulatory action but to allow such action to be implemented more effectively. Typical issues* that MAP3S must address are:

- Distances over which pollutants can be transported (and, therefore, over which controls must be implemented)

- Relative roles of nitrogen oxides and sulfur oxides in affecting precipitation and secondary pollutant formation

- Relative roles of emissions from power plants and other sources

- Presence of particular chemical species causing the health effects (so that the proper controls can be implemented)

- Kelative roles of other particles in neutralizing acid species (controls on fly ash may result in less material to neutralize acidic sulfur compounds)

- Frequency of episode conditions, and their relative importance in causing increased annual concentrations (for use in evaluating biological and health effects).

MAP3S, in addressing these issues, will provide the sound scientific basis for promulgating and effectively implementing the very likely expensive control techniques.

\subsection{STATUS OF RESEARCH IN FOSSIL-FUEL EMISSIONS}

DOE has designed the MAP3S research program to address the many complex problems related to the atmospheric pathways followed by emissions from fossilfuel power plants. In doing so, DOE recognizes that considerable research has been

\footnotetext{
-Some of these issues are discussed more fully in the following section.
} 
done in some areas, including important contributions by DOE itself, and that other organizations are also planning to increase their research efforts in these areas.

- In the past few years, most studies of the fate of sulfur emissions in the United States have addressed problems of the urban scale and slightly beyond. The latter includes specialized studies of power plant plumes, to isolate sulfur-dioxide-tosulfate transformation processes. The most recent major program on the urban scale has been the Regional Air Pollution Study (RAPS), sponsored by EPA. Detailed source emission, meteorological, and air quality data for the metropolitan St. Louis area are being developed in that study, to test assumptions and representations concerning the many processes that affect urban air quality. On a slightly larger spatial scale, the METROMEX project (Changnon et al., 1971; Changnon and Semonin, 1975) focused the research efforts of several organizations on the potential for weather modification by (and implicitly the pollutant transport from) the greater St. Louis metropolitan area. More direct interest in pollutant transport was exhibited by the Fate of Atmospheric Pollutants Study (Breeding et al., 1973), which also concentrated on St. Louis as a pollutant source.

On larger scales, major studies in Europe (e.g., Bolin, 1971; Ottar, 1976; Prahm et al., 1976) clearly demonstrate the importance of long-range transport in the atmospheric sulfur problem. Recent preliminary data indicate that long-range transport from North America to Europe may be occurring (Nyberg, 1976). Analysis of observations (e.g., Wexler, 1950; Volz, 1969; Hall et al., 1973; Husar et al., 1976a) and limited expeditionary field experiments with aircraft (e.g., Brown and Garber, 1976; Alkezweeny and Powell, 1977) and manned baloons (Zak, 1976) in the United States indicate that pollution problems are often regional and perhaps subcontinental in scale. The EPA is also undertaking, in coordination with RAPS, an exploratory program of several years' duration (the Midwest Interstate Sulfur Transport and Transformation Experiment - MISTT); the program is investigating the interaction of atmospheric processes and sulfur compounds along trajectories to distances beyond $100 \mathrm{~km}$ (White et al., 1976). MISTT is being considered as a basis for an expanded program after RAPS (EPA, 1977). Each of the above studies indicates that pollutants are being transported more than $100 \mathrm{~km}$ - results that clearly point to the potential importance of investigating effects over even larger distances.

The increased need for atmospheric research on scales beyond $100 \mathrm{~km}$ is recognized by EPA, EPRI, and DOE. In particular, EPA is charged with improving and maintaining air quality, and EPRI must provide a technical basis fơ planning by the electrical utility industry. Although these organizations and DOE have slightly different long-range objectives, the necessary scientific research for developing the needed understanding has much in common.t Thus, MAP3S intends to coordinate its research program, and especially the field experimentation and observation subprograms, with related activities of other domestic organizations and groups (refer to CEQ, 1976). Also, it hopes to interact with Canadian, European, and other international research programs.

\subsection{SULFUR OXIDES AND OTHER POLLUTANTS}

In the broadest context, MAP3S aims to improve the capability of assessing the effects of the entire set of pollutants that results from the combustion of fossil fuels in producing electric power. MAP3S will focus primarily on sulfur oxides. But, to a 
large extent, the research results will be applicable to the other categories of pollutants. For example, the numerical modeling of transportation on continental scales will be directly transferable to the treatment of other pollutants. Because the factors governing $\mathrm{SO}_{2}$ transformation to other oxidized states may depend on such parameters as trace metals, particle loading, and photochemical activity, we will also measure a wide range of other variables as part of the present phase of the MAP3S program. This will help in transferring capabilities to treat other pollutants, but not just in one direction; for example, DOE's program experience in the long-range transport of radionuclides will be applied to assist in model verification.

\subsection{EXPERTISE IN DOE NATIONAL LABORATORIES}

In the past, the study of both atmospheric chemistry and physics has received considerable support from DOE. This means that significant capabilities, which to some extent have been applied to the study of sulfur oxides, exist for rapid and effective application now for further study of sulfur oxides. For example, in the past several years, DOE laboratories and contractors have:

- Studied sulfur transformation rates in major point source and urban plumes (Newman et al., 1975; Schwartz and Newman, 1977; Alkezweeny and Powell, 1977)

- Studied the evolution of the planetary boundary layer and its capability to isolate pollutant layers aloft (Hess and Hicks, 1975)

- Applied eddy-correlation methods to the direct measurement of fluxes at the surface (Wesely and Hicks, 1977a)

- Developed instrument techniques that can determine the molecular form and other characteristics of sulfur oxides (Marlow and Tanner, 1976; Craig et al., 1974; Cunningham et al., 1975)

- Investigated the scavenging of atmospheric particles by precipitation (Semonin, 1972; Gatz, 1974; Dana et al., 1975)

- Studied the acidity of precipitation on an urban scale (Semonin, 1976)

- Developed numerical models that provide preliminary assessments of sulfate distribution on continental scales (Heffter et al., 1975; Wendell et al., 1976; Meyers et al., 1976; Sheih, 1977)

- Participated in research on the deposition of pollutants from urban areas (Changnon and Semonin, 1975).

Note that the field experiments and modeling capabilities have been tied together in addressing the various problem areas. The above capabilities, when utilized in achieving the MAP3S goal, will provide a firm basis for improving our knowledge of the fate of sulfur oxides when transported on multistate scales.

\subsection{AVAILABLE RESOURCES}

The MAP3S program is organized as a major programmatic effort of DBER. The core program at the DOE national laboratories is about $\$ 2.8$ million for FY1977 (see Appendix B), with about $\$ 400,000$ allocated to universities and other organizations. This funding level was achieved largely by combining and 
redirecting current research in the laboratories, rather than by infusing new funding. As the program evolves and as fúnding permits, the present effort will be augmented by further involvement of other government agencies and university research organizations.

Given the $\$ 2.8$-million budgetary level, we feel that we will achieve a more significant advance by focusing research on sulfur oxides and closely related compounds instead of spreading it over several categories of pollutants.

By concentrating on atmospheric sulfur compounds, we will respond to both the opportunity for significant progress and the national concern these areas have drawn because of their detrimental effects on human health and the general environment. The MAP3S research program we describe in the next section is structured to respond effectively within the context of DOE's capabilities and resources. 


\section{THIS PAGE}

WAS INTENTIONALLY

LEFT BLANK 


\section{MAP3S SCIENTIFIC PROGRAM - RESPONDING TO UNCERTAINTY}

As mentioned before, the MAP3S program is designed to improve the capability of numerically simulating the atmospheric effects of coal combustion (primarily, coal combustion from generating electric power). Because the ultimate policy issues involve pollutant effects, not just their concentrations, the program's research priorities should perhaps be developed from the requirements of the studies of the health and ecological effects that could result from the atmospheric pollutants. But important data are lacking. Available data on some effects are too sparse (e.g., on the response of forest ecosystems to particular characteristics of modified precipitation chemistry). Also, uncertainties in such effects are too numerous (e.g., what pollutant species cause what health effects). Until more data become available and the uncertainties are reduced, we cannot define particular questions or establish priorities concerning, for example, the relative importance of long-term average and short-term episodic conditions, pollutant particle size and composition, and instantaneous or storm-average precipitation acidity.

Indeed, in planning the MAP3S atmospheric research program,we cannot rule out any one process or pollutant species as being significantly more or less important than another. Therefore, our approach is to identify those aspects of the problem where uncertainties remain; also, to devote theoretical and experimental studics to all potentially significant pollutants and to all atmospheric mechanisms controlling the transport, transformation, and removal of energy-related emissions.

Conceptually, the tasks we must carry out to alleviate uncertainty and improve our understanding of relevant atmospheric behavior are divided into three subprograms:*

- Characterization subprogram: to measure the chemical and meteorological variables that determine the distribution of pollutant species and that will be needed as input for, and as a means of, verifying numerical model simulations.

- Field experiments subprogram: to design and execute atmospheric research experiments which are necessary for understanding the mechanisms and related processes that must be included in simulation models to improve their accuracy.

- Simulation subprogram: to develop, verify, and demonstrate the capability to simulate the atmospheric bchavior, pollutant concentrations, and precipitation chemistry effects of emissions, from fossil-fuel electric power production, especially those that are relevant to human health and welfare.

-A laboratory subprogram is not included in MAP3S, although other DOE divisions may support relevant fundamental research. However, we will make substantial efforts to improve and hetter understand instrument techniques. We expect to apply these techniques in observing the atmosphere, which is why we include them implicitly in the characterization and field experiments subprograms. 
We anticipate that these subprograms will be carried out simultaneously. For example, we will develop a repertoire of characterization measurements even as we are constructing the numerical models and testing them against measurements from the field program. We recognize that the dividing line between field and characterization measurements may not always be sharp but, conceptually, this distinction should be recognized. As an example of this distinction, the determination of pollutant deposition rates as a function of meteorological parameters (e.g., temperature gradient, gustiness, etc.) falls into the field experiments subprogram. The determination of meteorological parameters for model calculation inputs constitutes a characterization measurement.

Within the framework of the three subprograms, we have identified the quantities and processes (Fig. 2) under investigation in this study. The arrows in Fig. 2 indicate the influence of one quantity or process on another and are not necessarily exhaustive. For example, the figure indicates the potential effects of atmospheric concentrations on the rates of transformation processes, and the effects of transformation (e.g., aerosol growth) on removal. However, the possibility of weather modification affecting wet removal rates is not indicated.

The goal of MAP3S includes the understanding of these physical processes, as cvidenced by the development of a verified simulation capability. Thus, the simulation will be a quantitative mathematical representation of the physical processes and quantities indicated in Fig. 2. We will verify the models by comparing the simulated atmospheric concentrations and consequences with those measured in the characterization studies. When we reach the goal of an improved, verified model, we will exercise the model with various scenarios of fossil-fuel electric power production, including different geographical distributions, fuel characteristics, control strategies, etc. Study results (i.e., simulated atmospheric concentrations and consequences) will be made available to the community, within and outside DOE, that deals with the effects of such concentrations and consequences on human health and ecology.

\subsection{MAP3S RESEARCH TASKS}

Based on the set of processes and data needs identlfled in Fig. 2, we have identified 10 program elements thăt arè ôf particular importance lu gaining a iñuchì better understanding of the role of fossil-fuel combustion in affecting the atmosphere.

The 10 elements, or tasks, are integral to the 3 subprograms, but to some extent they also transit the 3 subprograms. They are the research efforts that we expect will help in providing the basis for environmentally evaluating the release of AER pollutants.

Present DOE budget levels, however, will necessitate a research focus on tasks leading to a rapid improvement in understanding. As a result, some areas (e.g., weather and climate modification by pollutants) will not receive the research allention they deserve, although other government programs may partially address them. Also, existing tasks funded by other organizations (e.g., EPA and EPRI) are making significant contributions. In such cases, DOE will not overlap research activities by undertaking major new initiatives. Instead, it will either rely on their results or help augment their programs. 


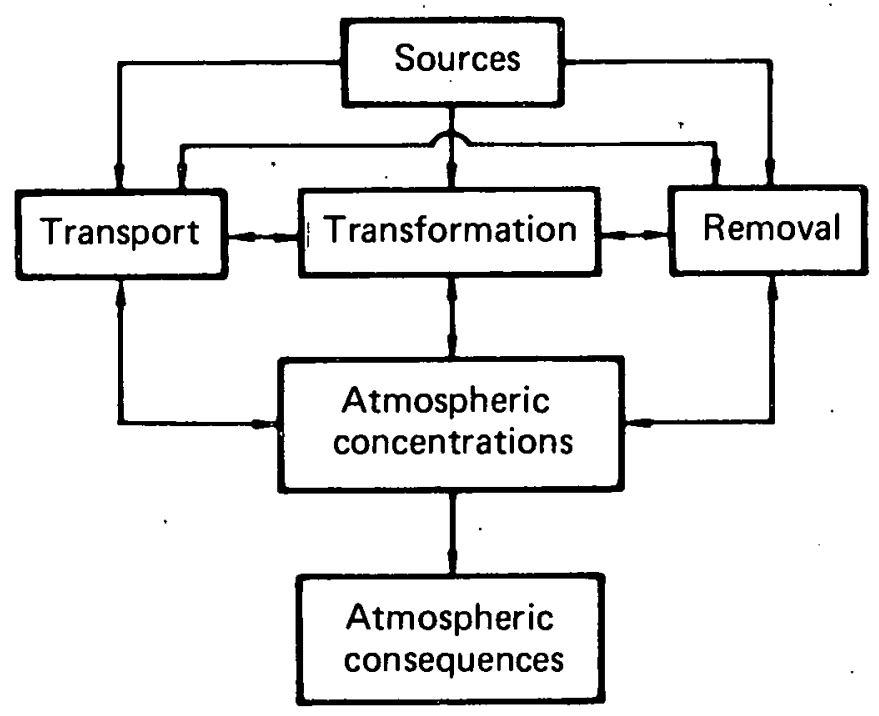

Sources

Type:

- Energy-related

- Anthropogenic, nonenergy

- Natural

Characterization:

- Chemical species

- Spatial and temporal

Atmospheric concentrations

- Chemical species

- Physical state, e.g.,

- aerosol size

- Spatial and temporal
Transport

- Determine relevant physical processes

- Vertical mixing

- Long-range transport

Transformation

- Determine mechanism and rate of chemical and physical processes

Removal

- Dry deposition

- Wet deposition

Atmosphcric consequences

- Air quality

- Precipitation chemistry

- Weather and climate

- Visibility

FIGURE 2-Atmospheric processes - MAP3S subprograms. 
In formulating the work program for the identified tasks, DOE laboratory researchers have sought to recognize the various hypotheses that are offered to explain such contradictions as the general constancy of regional sulfate levels despite the recently observed decrease in urban sulfur dioxide levels (Altshuller, 1976). One particularly interesting explanation of this paradox is that the increased use of tall stacks has led to an extension of the average time that the emitted sulfur dioxide remains in the atmosphere, thereby increasing the opportunity to form sulfate aerosol and magnifying the impact on air quality at long distances downwind. Some of the other hypotheses, put forward to explain the "sulfate anomaly," relate to reactions with unaccounted-for emissions, increasing photochemical oxidation rates in polluted areas, instrumental problems, sampling errors, inadequate understanding of transformation phenomena, and unrecognized natural sources of gaseous sulfur and sulfate (Siliwartz, 1976).

The subsections below discuss the identified MAP3S tasks in terms of the level of understanding in each area and the research response that is planned. Tasks I through 4 (and part of Task 8) fall largely into the characterization subprogram; Tasks 5 through 9 come under the field experiment subprogram; and Task 10 encompasses the broad numencal modeling and anaiysis efforts of tlie simulation subprogram.

\section{Task 1 - Power Production Emissions}

To specify and quantify the emissions of AER pollutants from present power production plants, and to consider pollutants that may be emitted as a result of an increased usage of coal and the introduction of new power production processes, e.g., fluidized bed combustion and MHD systems.

About 200 fossil-fuel-fired power plants are located in the Greater Northeast, the largest of which are shown in Fig. 3. An evaluation of the impact of the emissions from these power plants on current air quality requires an accurate inventory of the emitted compounds and their amounts. Direct measurements of emissions at particular times have been made both in stacks and in the region immediately downwind from a number of power plants (e.g., Ragaini and Ondov, 1976; Davis et al., 1974). But for most power plants, available emission data for the sulfur species are based on fuel analysis, combustion rates, and emissiun factors (c.g., see NEDS, 1976; NER, 1974; FPC, 1969, 1970, 1971, and 1972). These data do not reflect a particle size-breakdown of various pollutant emissions, an effect that may lead to important changes in emission rates of trace materials, depending on the type of control devices being used (Ragaini and Ondov, 1976). However, substantial uncertainty exists on the extent of combustion and postcombustion conversion of $\mathrm{SO}_{2}$ to sulfates - a process that may be affected by thc catalytic action of the stack walls, components in the fly ash, or by reaction with free radicals in the postcombustion gases. And this uncertainty is reflected in estimates of the sulfate emission rate. The differences in fuel use and physical design between power plants influence power plant emissions; also, changes in emission rate as a function of operating, maintenance, and environmental conditions, influence these emissions. Just as for the sultur compounds, uncertainiy exists fus puwer plant emissions of nitrogen oxides, polycyclic organics, and trace metals; and each substance may play a role in the transformation of other pollutants in the atmosphere and thus affect regional air quality. 


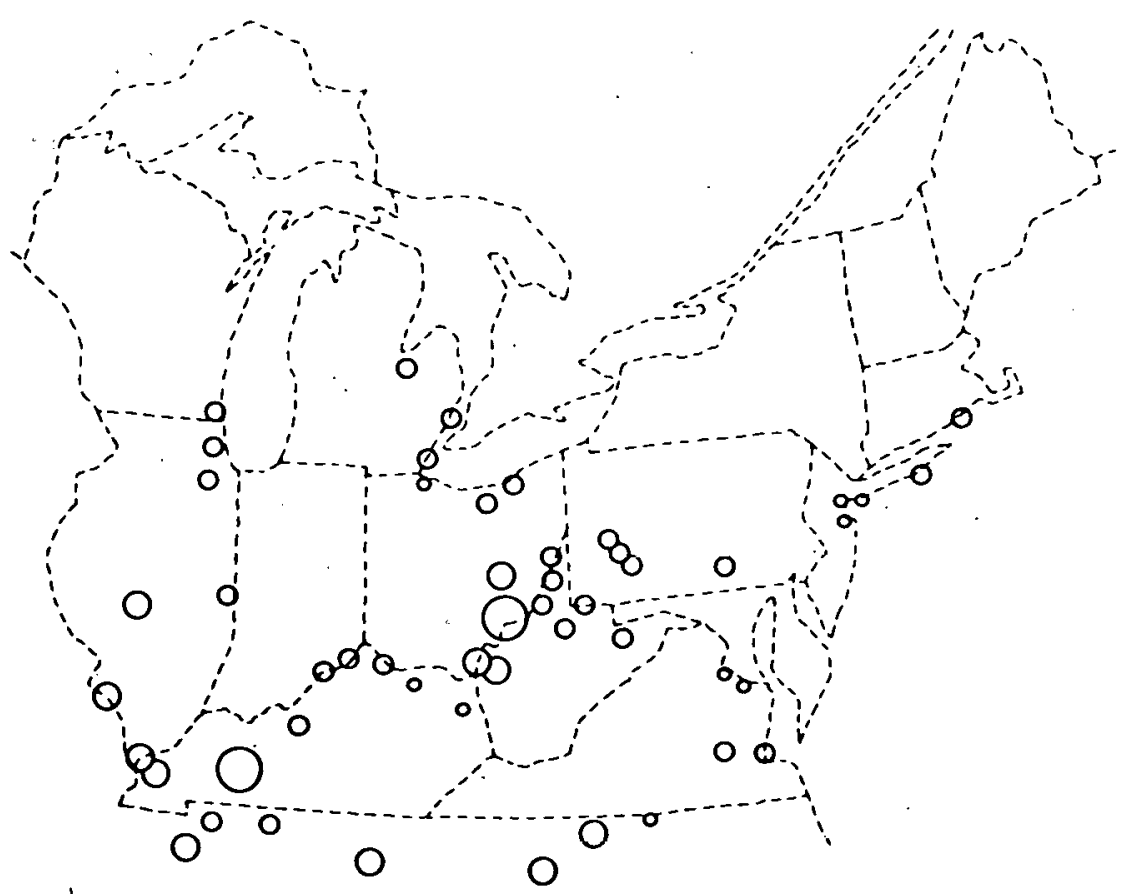

FIGURE 3-Emission strength and location of 53 major power plants in the Greater Northeast, based on 1974 data. Power plants are indicated by the circles. Emission strength is proportional to circle size. Largest circles indicate emission rates of 500,000 tons per year of $\mathrm{SO}_{2}$ (Sheih, 1977).

We plan to build a comprehensive data base of emissions for use in numerical model studies. It will contain the data base that BNL is now developing as part of the NCUA, as well as additional data being gathered by EPA and FPC. A preliminary look at the available data indicates that questions of completeness, accuracy, grid location, and avoidance of duplicate entries need resolving. Work on the new inventory being developed as part of the SURE program will be followed closely. Wherever feasible, we plan to interface information from current and future studies, relating emissions to plant operational parameters (e.g., by BNL on coal- and oil-fired power plants), with the data base inventory. Note that it will be possible to apply MAP3S-developed methodologies to advanced combustion and coal technologies, but only if the respective source emission terms are characterized adequately.

\section{Task 2 - Nonpower Production Emisions}

To identify and quantify sources of pollutants that do not stem directly from power production but that may affect the concentration, distribution, transformation. and fate of $A F R$ pollutants.

Pollutants released in the course of power production must be viewed in terms of both their specific impact and their impact in the context of other pollutants released to the atmosphere. Other pollutants, both natural and artiticial, provide 
ambient pollutant levels into which the AER pollutants are released. But they can also affect the processes of transformation and wet and dry removal that act on AER pollutants. Therefore, we need to develop a comprehensive picture of the atmospheric budgets (i.e., emission, transport, transformation, deposition and fate) of such elements as sulfur and nitrogen on the regional scale.

Detailed emission inventories of species that can interact with and transform identified AER pollutants are necessary in developing this picture. As a first step, we will develop an inventory of sulfur, nitrogen, and hydrocarbon compounds from the best available, already compiled, data bases (e.g., EPA's NEDS data base, state inventories, etc.). Sources include space heating, commercial and industrial processes (e.g., refining), gasoline combustion, and other fugitive sources (e.g., construction and abrasion). Such parameters as height of emission, seasonal and daily patterns, etc., will be included if they are available. Wherever possible, we will also include sources of potential catalytic materials, e.g., metal oxides from ferroalloy plants. We will focus mainly on compiling data from available inventories; initial efforts have been made for the NCUA program at BNL and will be continued as part of MAP3S.

Numerous researchers have computed global sulfur budgets (e.g., Junge, 1972; Friend, 1973; Granat et al., 1976; Bolin and Charlson, 1976). Few measurements (e.g., Georgii et al., 1976) of the magnitude of sulfur emissions from natural biogenic and marine processes on the global scale have been made, and considerable uncertainty remains. Such compounds as hydrogen sulfide $\left(\mathrm{H}_{2} \mathrm{~S}\right)$ and dimethyl sulfide $\left[\left(\mathrm{CH}_{3}\right)_{2} \mathrm{~S}\right]$ have been suggested as important sulfate precursors on a regional scale (Hitchcock, 1976). We plan to evaluate the potential importance of such emissions, in affecting regional air quality, through model sensitivity studies. In these studies, the emission rate of sulfur compounds from identified marshland areas will be varied within realistic estimates. EPRI- and EPA-sponsored programs to measure natural emissions will be followed closely to refine the estimates of natural source emissions.

\section{Task 3 - Pollutant Properties}

To characterize the physical and chemical properties of $A E R$ pollutants commonly found in the atmosphere on a regional scale. These properties include particle size, oxidation state, derivative compounds, molecular form. etc.

The careful identification of pollutants found in the atmosphere is essential to adequately understand the role played by emissions from power plants and to determine the toxicity of the emissions. Directly emitted gaseous pollutunts (e.g., $\mathrm{SO}_{2}, \mathrm{NO}_{\mathrm{x}}$ ) have been sampled for many years. They have been followed out to tens of kilometers downwind from power plants. They are reasonably well characterized and, in most cases, have been controlled to such an extent that air quality standards developed by EPA are being met. For secondary, or derivative, compounds (e.g., ammonium sulfate and bisulfate, sulfuric acid mist, sulfite, etc.), most observations have been retlected in measurements of the tötal suspended burden. Relatively few sophisticated analyses have looked at such properties as molecular form, particle size distribution (usually, sulfur is found in particles smaller than $0.5 \mu \mathrm{m}$ ), acid sulfate speciation, oxidation state, associated cation, etc. In the cases of total sulfate burden and specific species concentrations, researchers have considered the 
possibility of pollutants transforming in the collection instrument or on the filter (e.g., Tanner and Newman, 1976). It may be such uncertainties and the limited amount of high-quality information that are causing poor correlations between atmospheric concentrations and health effects in community health studies.

The SURE program will use the best generally available techniques for particulates. Consequently, the MAP3S program will augment the SURE field meașurement program with sophisticated, laboratory quality sampling instruments and analysis techniques to help provide information on particle characteristics. We will use infrared spectroscopy (Cunningham et al., 1975), x-ray photoelectron spectroscopy (Craig et al., 1974), and Gran titrimetric analysis (Tanner and Newman, 1976) to look at such characteristics as particle acidity and molecular form; thermometric titration (Hansen et al., 1976) to look for S(IV) compounds (e.g., sulfites); and a diffusion battery (Marlow and Tanner, 1976) to provide samples for analyzing composition in various particle-size categories. Also, we will continue research to find the best possible analytic techniques to use and to make sure pollutant transformation is not occurring during collection or analysis. These studies will involve comparisons of interlaboratory techniques, sample exchanges, and the collection of duplicate samples.

In addition, we will analyze precipitation samples for a variety of pollutants that may stem from power plant emissions, as described more fully in Task 8.

\section{Task 4 - Pollutant Distribution}

To determine the spatial and temporal distribution of $A E R$ pollutants under both average and extreme conditions.

Federal, state, and local agencies, as well as various utilities and commercial groups, support programs to monitor concentrations. But their data are inadequate in space and time resolution to permit us to either verify numerical models or investigate important transport, transformation, and deposition processes. The most extensive set of data on sulfur oxide concentrations is probably that of the National Air Sampling Network (NASN), which includes a 24-hr sample taken every 12th day. These data were used in an analysis by Altshuller (1976). A utilitysponsored network analysis by Hidy et al. (1976) had a vailable daily data over a more limited region. Both studies pointed to the general location of elevated sulfate levels. But they were unable to provide clear evidence for either long-range transport or local pollutant deposition. Nor could they identify such specific subregional phenomena as urban or river valley pollutant plumes and the relative. influence of local and regional emissions. Measurements of the vertical pollutant distribution are even more sparse than those of the horizontal distribution. Consequently, we cannot identify circumstances that lead to such phenomena as the trapping of pollutants aloft by the nocturnal inversion, which might point to long-range transport of pollutants downwind.

Available data also do not adequately represent the variation in time of AER pollutants, nor do they identify local sources that may unduly influence individual observations. Pollution peaks lasting only several hours and multiday episodes may occur. Without proper time resolution, such events an be missed or poorly represented by the sampling network, which makes the assessment of health and ecological effects difficult. To complicate matters further, toxicological and 
ecological studies have not yet resolved the relative effects of short, intense doses and long, low-level doses. Until they do, measurements must cover temporal variations as fine as a few hours.

A greatly improved data base, describing the present concentration of pollutants (particularly sulfate) in terms of average and extreme conditions, is a recognized need of the MAP3S and SURE programs. The analysis of such a data base would give us an insight into the spatial extent of elevated pollutant levels, the regional coherence of polluted air masses, the selection of "episode" cases for model verification studies, and the data necessary for testing various hypotheses of sulfate transport and transformation. EPRI, assisted by its utility members, has focused the SURE program on the development of an extensive network of surface stations: 9 highly equipped stations, operating continuously for 19 months, and 45 lesser-equipped stations, operating during 7 month-long intensive periods. Pollutant distributions in the vertical domain will also be collected using aircraft, but on a more limited schedule of measurement operations during the intensive periods than that of the surface network.

We plan to devote substantial MAP3S resources to expanding aircraft observations in order to provide us with the needed data to represent the horizontal and vertical extent of pollutants above the earth's surface. For example, we will fly vertical profiles and horizontal traverses above and within the surface mixed layer, during a variety of specially selected patterns of atmospheric flow (e.g., polar continental, maritime tropical, etc.). The observed pollutant patterns will be used to estimate such quantities as the flux of pollutants into the NY/Washington megalopolis from the Ohio River Basin and from the southeast, the west, and the north. Such planned flights are intended to characterize the pollutant patterns in various air masses. To every extent possible, we will coordinate them with the location and operational schedule of the SURE network and aircraft, to develop the comprehensive data base of present air quality that is needed for model verification.

MAP3S resources will not be used to augment the number of fully equipped surface monitoring stations in the Greater Northeast. But in planning which stations to select for some DOE instrumentation, we will utilize an ANL capability to assess objectively the adequacy of station siting patterns. Also, as described in Task 3, we will provide some monitoring equipment and will undertake a special quality-assurance program to make sure that the observations and techniques are of the needed quality.

\section{Task 5 - Pollutant Transport}

To determine the processes and parameters governing the vertical and horizontal transport of AER pollutants.

The disposal of combustion products in the atmosphere depends on dispersal occurring both horizontally and vertically to reduce near-source concentrations, and mainly horizontally to reduce distant concentrations. For point sources with simple physical, topographic, and meteorological conditions and with nonreacting pollutants, the relatively simple Gaussian formulation, employing the well-known Pasquill-Gifford stability classes (Gifford, 1976), has proven reasonably adequate for representing close-range atmospheric effects on pollutant transport. But for tall 
stacks, reactive pollutants, complex terrain, and when vertical layering of the atmosphere is important, we need a better understanding of how the atmosphere transports such pollutants and mixes direct power-plant emissions with pollutants from dispersed sources already present in the air mass.

Studies downwind of St. Louis have been made with aircraft (White et al., 1976; Alkezweeny and Powell, 1977) and a manned balloon (Zak, 1976). Also, studies downwind of Milwaukee (Alkezweeny, 1977a) and the east coast (Brown and Garber, 1976) have been made with aircraft. They all indicate that pollutants emitted by cities form plumes extending at least $100 \mathrm{~km}$ downwind. Early analytic results of the SURE program (Hidy et al., 1976) show that "The zone of influence of an individual source on the concentration values for the sulfur oxide particulate complex (SPC) appears to be 200 to $300 \mathrm{~km}$ weighted toward the downwind direction." Visibility and trajectory studies (e.g., see Hall et al., 1973; Husar et al., 1976a) and inert and radionuclide tracer releases (Knox et al., 1971; Cowan et al., 1976) reveal that pollutants can be transported to even longer distances in the lower atmospheric levels, before removal processes deplete concentrations to background levels.

The vertical dispersal of pollutants is equally complex. Diurnal changes in atmospheric stability lead to the vertical dispersal of pollutants up to several kilometers during daytime mixing periods. During nighttime periods, they lead to the isolation of pollutants aloft, as low level nocturnal inversions are formed (e.g., see Hess and Hicks, 1975). Depending on wind speed and direction, these isolated pollutant layers can be transported long distances during nighttime hours, evidenced in the flight of a manned balloon (da Vinci Program) in 1976 (Zak, 1976). The pollutants contact the surface when subsequent daytime mixing takes place. Vertical motions in nonprecipitating clouds can also mix pollutants higher in the atmosphere, where horizontal wind speed is usually greater.

The discovery that long-distance transport occurs on some occasions was a significant technological achievement in itself. But what is more significant is understanding the mechanisms that interact to produce such transport and the parameters that determine whether such transport will occur under particular conditions. This understanding will require further field and modeling studies. Also, instances of long-range transport have been identified under relatively straightforward meteorological and physical conditions. Yet they must also be occurring under more involved conditions marked by complex terrain, frontal movement, and coastal meteorological regimes that occur in the areas showing elevated sulfate concentrations.

I he MAP3S research plan includes field experiments that are designed to focus on improving our understanding of the horizontal and vertical processes leading to long-range transport. One is a recent field program of ANL, which has studied early morning inversion break-up and early evening reformation (see Fig. 4). This program will be continued to study events over continuous periods of several days, to gain a better understanding of vertical pollutant dispersal. We are planning to augment this field program with an inert tracer experiment and aircraft measurements of pollutants in layers aloft. Separate exploratory studies of the distribution of pollutants aloft will also be undertaken by BNL, as part of regional studies of the pollutant budget upwind and downwind of such urban areas as New York. The objective of these studies is to develop a representation 


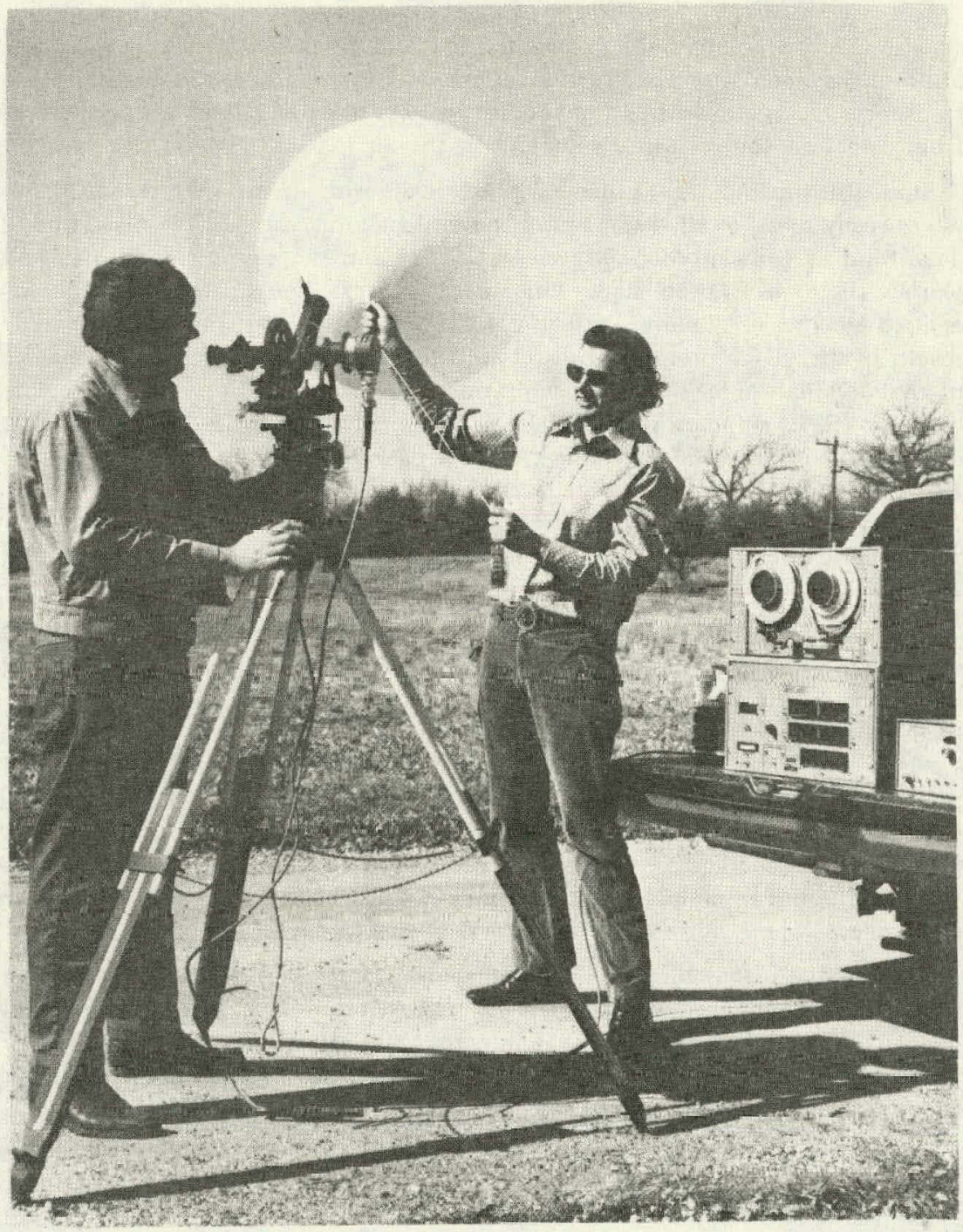

FIGURE 4-MAP3S researchers from Argonne National Laboratory prepare to release and track a small balloon that contains a miniature instrument for measuring temperature. Optical tracking provides information on wind and height, thus adding to the data available (ANL photo). 
of the atmosphere's vertical mixing parameters for use in numerical models. The study of mospheric stability and its effect in limiting interactions of pollutants at the surface will be of particular interest.

Horizontal dispersal mechanisms are being investigated in a DOE-supported cooperative effort by ARL, BNL, EML, and LASL.* The cooperative goal is to develop a practical system for sampling and analyzing special tracers at very low concentrations. Laboratory tests of prototype instruments for perfluorocarbon tracers are under way. Field tests planned for FY-1977 are designed to demonstrate an instrument capability of measuring the tracers at $50 \mathrm{~km}$. Similar progress is being made by LASL using "heavy" methanes. Eventually, we plan to conduct tracer experiments at distances from 500 to $1000 \mathrm{~km}$. The objective of these studies is to detail and confirm the time and spatial domains over which pollutants disperse, especially in complex terrain (e.g., Allegheny Mountains) where channeling and flow diversion can occur. It is conceivable that various anthropogenically emitted pollutants (e.g., trace metals) could be used instead of waiting for measurement capability to be developed for these special tracers. But severe constraints, imposed by the lack of experimental control over such parameters as timing, release period and location, and other sources of these pollutants, prevent their use in long-distance experiments. Therefore, we plan to use such pollutants as tracers of horizontal motion mainly over short distances and incidental to other experiments.

To complement these empirical approaches in understanding atmospheric transport phenomena, numerical modeling studies are under way. Trajectory models have been used to investigate various aspects of the transport problem, as shown for example in Fig. 5, where the effects on plume dispersal, using winds at different altitudes, are compared. Such results point to the need for determining what levels, in the vertical, will be reached by the pollutants, particularly emissions from tall stacks. This sensitivity to a knowledge of the wind field (a similar sensitivity exists that depends on vertical structure) has led to modeling efforts to determine the wind field more satisfactorily than can be done from the routine 12-hr radiosonde releases.

Building on work done for the Army, Meyers et al. (1976) have developed a diagnostic mesoscale model, using mass and total energy conservation constraints to provide self-consistent wind fields and mixing height fields in a layered structure through the troposphere. The MAP3S program will support the continued development of this model. Development of a data base, to verify the model, will require a major field program in a region of complex terrain during situations where changes in wind speed and direction are above the range of uncertainties caused by measurement error and short-term temporal variability. In FY-1978, we will assess the feasibility of such a field experiment, tentatively planned for the Allegheny Mountains, which lie between the emissions in the Ohio River Valley and the potential recipients of such emissions in the New York area. The experiment will augment existing meteorological surveillance for direct verification of the model, and it will use results from tracer and pollutant observations for indirect verification. Its success will depend on availability of additional funding, participation of other organizations, and close cooperation among researchers.

*LASL also receives support for these studies from other organizations. 
$1200,04 / 1,9 / 74$

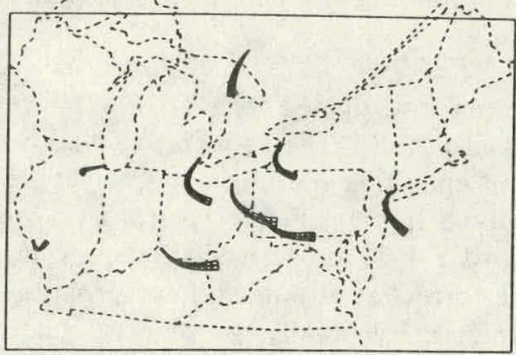

$0000.04720 / 74$

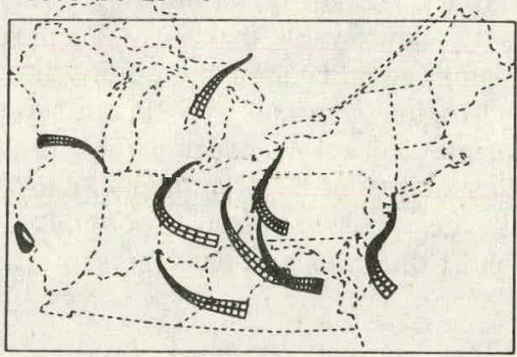

$1200.04720 / 74$

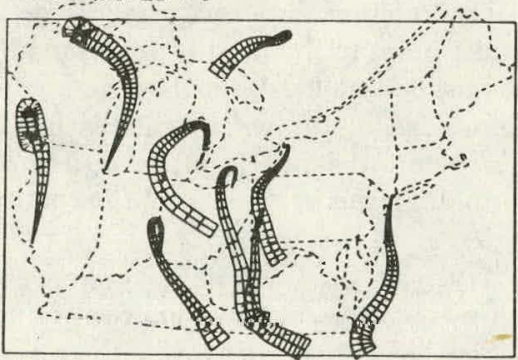

$1200+84790-7$

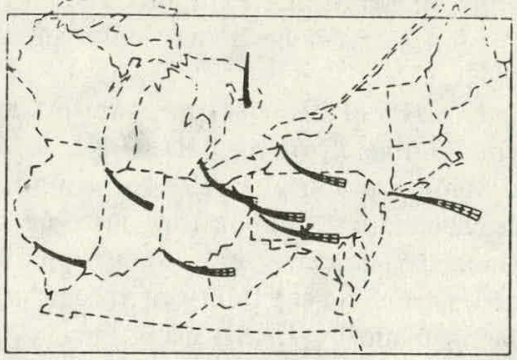

$0000 \quad 04780 / 74$

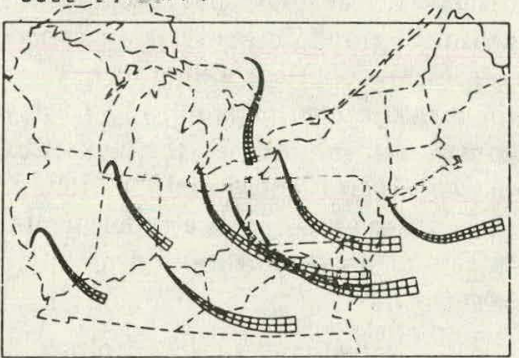

$1200,04780 / 74$

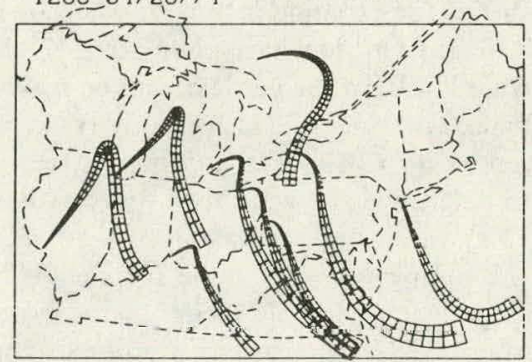

FIGURE 5-Trajectory model results, showing a streaker trace through particles ejected hourly from nine point sources. Plume width is calculated with the use of stability-dependent diffusion coefficients. The figures outside the boxes indicate a 24-hr sequence at 12 -hr intervals. The left column of boxes shows results that use winds averaged over the 100 - to $1000-\mathrm{m}$ layer; the right column shows results that use the winds at $850 \mathrm{mb}$ (Wendell et al., 1976). 


\section{Task 6 - Pollutant Transformation}

To identify the chemical and physical transformation processes affecting $A E R$ pollutants, and to determine the rates and mechanisms controlling such processes.

- Methods of attaining acceptably low atmospheric concentrations of pollutants directly emitted by power plants (e.g., sulfur dioxide) have included the reduction of emissions and use of indirect control measures (e.g., tall stacks, rural location of power plants, etc.). Unfortunately, these approaches to improve air quality have not succeeded in reducing some of the derivative, or secondary, species* formed from chemical and physical transformations taking place in the atmosphere after emission. This nonlinearity, for example, between emissions (and, therefore, concentrations) of $\mathrm{SO}_{2}$ and concentrations of $\mathrm{SO}_{4}^{-}$(as shown in data discussed by Altshuller, 1976), requires us to understand the detailed mechanisms involved and to establish reaction rates before an expensive control program is mandated to improve air quality. Only a small fraction of the emitted $\mathrm{SO}_{2}$ needs to be converted to $\mathrm{SO}_{4}^{=}$to account for present sulfate levels. Consequently, given the present uncertainty $y_{i}$ and disagreement about the relative roles of various transformation mechanisms, the success of a proposed control program will depend on an improved understanding of the postemission, atmospheric transformations.

Transformation processes can be either physical or chemical. Physical processes usually include such phenomena as particle coagulation, agglomeration, and growth. Chemical processes can be either homogeneous or heterogeneous. Their respective roles must be clarified. The most desirable approach to find out what part each process plays in affecting AER pollutants is to couple theoretical analysis with laboratory studies, and then have the results agree with atmospheric measurements to mark its success. Such an approach, though, involves many practical problems (e.g., oversimplifying theoretical investigations, assuring that the experimental chamber does not affect the results, and making sure that such important atmospheric properties as fog, clouds, sunlight, atmospheric turbulence, etc., are included). Nevertheless, a great deal is being learned in experiments using such an approach, especially in the case of homogeneous processes in photochemically active atmospheres (Roberts and Friedlander, 1976). Our understanding of heterogeneous chemistry, however, is still far from satisfactory, although progress is being made. MAP3S recognizes the on-going efforts of EPA and other groups in this area. Accordingly, we will undertake only specific theoretical and laboratory studies that may shed additional light on the results of field experiments. A particular example, now being supported at ANL, is one in which oxygen isotope ratios are being measured (Holt et al., 1976; Holt, 1977). By looking at such ratios in atmospheric water vapor, sulfur dioxide, and sulfate, and then comparing laboratory results (obtained under controlled conditions) with field data, we expect to increase our understanding of the mechanisms that convert $\mathrm{SO}_{2}$ to sulfate. For example, we will use this approach to examine heterogeneous transformation processes in clouds. Only a small percentage of clouds actually precipitate. But the transformation process taking place in nonprecipitating clouds, if significant, could contribute to aerosol generation on a regional scale.

\footnotetext{
- In this discussion, we assume sulfate to be a secondary pollutant, even though at least small concentratiuns of it (about 1 to $3 \%$ ) are emitted directly.
} 
We will direct the major MAP3S research effort toward a field program that attempts to identify certain conditions, where the effects of transformation processes on pollutant concentrations can be determined independently from the effects of other processes. These conditions are: point source plumes, urban plumes, and box budgets.

The plumes of power plants have been studied for a number of years (e.g., Davis et al., 1974; Gartrell et al., 1963; Husar et al., 1976b; Newman et al., 1975), with a variety of results. The diversity in results is attributed to such variables as the concentration of other pollutants (e.g., metal catalysts); relative humidity, temperature, sunlight, time of day, atmospheric mixing, and fog. The most complete set of currently available data represents 30 case studies at four different coal-fired power plants (Forrest and Newman, 1977). The results show "[n]o distinct correlation ... between the extent of sulfur-dioxide conversion [and] distance from source, travel time, temperature, relative humidity, time of day or atmospheric stability" (see rig. 6). "i his läck of correlation could be consirued as

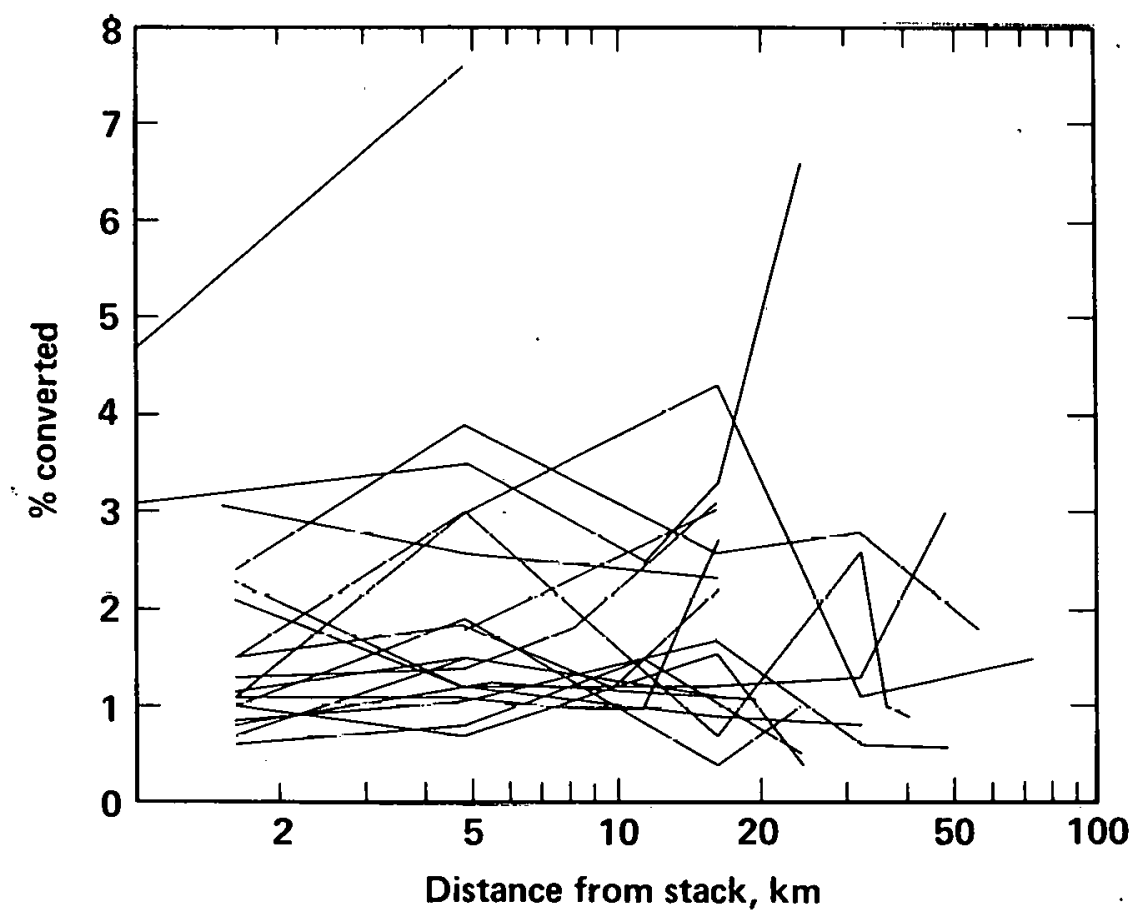

FIGURE 6-Observed conversion rate of $\mathrm{SO}_{2}$ to sulfate, with distance, on 21 different days for the Union Electric Company plant in Iahadie, Missnuri (Forrest and Newman, 1977). Possibly, because of a limited range of atmospheric conditions, no distinct correlation could be found between the extent of $\mathrm{SO}_{2}$ conversion and distance, travel time, temperature, relative humidity, time of day, or atmospheric stability. 
pointing to some heterogeneous catalysis mechanism (shown in liquid phase chemistry in the laboratory and in some field experiments). But the range of variation of the different parameters in the experimental data still leaves considerable uncertainty about whether homogeneous mechanisms (e.g., photochemical processes involving $\mathrm{OH}$ ) are also occurring. For example, a number of studies seem to point quite directly to homogeneous mechanisms instead of heterogeneous mechanisms (e.g., Davis et al., 1974; Husar et al., 1976b). Further, recent evidence suggests that sulfite may be more stable than sulfate in the plume, and that the formation of the sulfite species may be much more important than previously supposed (Eatough et al., 1977).

The MAP3S program, in cooperation with research sponsored by EPA and other organizations, will undertake to expand the range of conditions for which power-plant plume data are available. Added conditions are winter sun, nighttime, very high humidity, and more highly turbulent situations. Also, we will analyze for a greater variety of species (e.g., sulfite). Our objective is to understand the transformation mechanisms of sulfur dioxide (and other pollutants) on scales of several hours and out to $100 \mathrm{~km}$ or more, in a framework of relatively noninterfering, background pollutant levels.

Pollutant transformation also occurs in urban plumes, whose polluted air may interact with, or serve as the ambient environment for, power plant plumes. As a result, a number of studies have looked at changes in species concentrations in urban plumes. Studies by Hidy et al. (1974), Alkezweeny (1976, 1977b), and by White et al. (1976) indicate that sulfur dioxide oxidation apparently occurs at a measureable rate - typically, several times the rate found in power plant plumes although a wide range of rates has been suggested for different conditions. In addition, measurements of the oxidation show the change in particle size distribution as evidence of physical transformation. Because there are many potential interferences in results from urban plume studies over land (e.g., variations in surface deposition, and new sources), MAP3S is sponsoring a studyof urban plumes over Lake Michigan and downwind of Milwaukee. As part of the study, several weeks of measurement were carried out, during the late summer of 1976, using two PNL aircraft and other cooperating surface and aircraft platforms. MAP3S will support continued urban plume studies in the Greater Northeast, to provide information under a variety of meteorological conditions. These studies will include the interaction of point source plumes with urban plumes and of urban plumes with each other.

The third condition, in which the effects of transformation processes on pollutant concentration in the real atmosphere can be determined independently, is the box budget. We plan to construct a hypothetical fixed box* and calculate the mass balance of each species within the box over some period of time. Initially, such box budget experiments will include relatively simple regions and meteorological conditions. Surface and aircraft-based measurements will be taken to determine pollutant fluxes into and out of the top, bottom, and sides of the box. In such experiments, because transformation mechanisms are determined as a remainder term, particularly accurate measurements are needed. We anticipate being able to classify box budget results by air mass type. Although these

\footnotetext{
-As uppused to the muving box of air treated in the point source and urban plume expenments.
} 
experiments are difficult, the information from them will be useful in verifying numerical models, one class of which deals with fixed boxes through which air and pollutants flow. During FY-1977, MAP3S will support a first-phase box budget experiment on the scale of $100 \mathrm{~km}$ to test feasibility. In future years, we will make such experiments more comprehensive (in terms of the types of measurements taken) and more complex, when we focus on such regions as river valleys and on meteorological conditions conducive to sulfate episodes.

In improving our understanding of transformation processes, MAP3S will continue on-going DOE programs to improve the capability and quality of measuring pollutants under field conditions, and to ensure that what is measured is indeed what is present in the atmosphere (see Task 4).

\section{Task 7 - Surface Romoval Processes}

To determine the rates of physical and biochemical mechanisms governing the removal of $A E R$ pollutants from the atmosphere at the earth's surface (dry deposition).

Various processes remove gaseous and particulate pollutants at the earth's surface. Their removal rates appear to be related to such variables as: surface character (Chamberlain, 1966, 1968: Garratt and Hicks, 1973; Garland, 1977); atmospheric stability (Hicks and Liss, 1976); turbulence; time of day; pollutant concentrations; and other factors (Wesely and Hicks, 1977a). Many of these interrelationships have been reviewed by Slinn (1977). Preliminary model experiments (e.g., Sheih, 1977) indicate that the rate of variation of these dry deposition processes, within uncertainty limits, can significantly affect downwind concentrations of pollutants and their derivative products. For example, vegetation is believed to absorb gaseous $\mathrm{SO}_{2}$ at a relatively high rate, compared to the scavenging of particulate sulfate. Thus, $\mathrm{SO}_{2}$ emissions close to the surface tend to be removed quickly near the source, where concentrations are high, leaving a retively small fraction available to be oxidized to form sulfate; also, $\mathrm{SO}_{2}$ emissions from tall stacks reduce local surface $\mathrm{SO}_{2}$ concentrations, allowing both more $\mathrm{SO}_{2}$ to remain in the atmosphere and more time for sulfate formation (Hales, 1976). Since sulfate is scavenged more slowly than is $\mathrm{SO}_{2}$, any increased opportunity for its production can cause increased concentrations, even if total $\mathrm{SO}_{2}$ emissions are not increased.

Traditionally, the processes that lead to pollutant deposition at the surface have heen lumped into a single parameter, referred to as the deposition velocity. Field experiments aimed at precisely determining this parameter as a function only of pollutant have mostly failed. Part of the reason for this failure is that the relevant processes must be divided into two categories: those that affect how fast the atmosphere transports pollutants to the surface and those that remove the pollutants once they reach the surface (where surface is meant to include the vegetation, structures, etc.). Because the removal processes may vary [e.g., sorption of $\mathrm{SO}_{2}$ by soils depends on soil characteristics (Bremner, 1976)] or become saturated (e.g., stomatal processes, which vary through the day depending on such factors as daylight, water balance, and temperature), it is nol enough to simply measure the properties of atmospheric transport. Nor is it enough to just measure surface properties, for under stable atmospheric conditions the pollutants may not be transported down into a plant canopy. For the complex, forested, field and 
urban geography of the Greater Northeast, there is a need for a much better representation of what is happening, in order for numerical models to simulate pollutant concentrations accurately.

It is worthwhile to understand, in detail, the mechanisms governing absorption and the other processes that remove pollutants at the surface, and DOE is sponsoring some ecological research to this end. MAP3S will coordinate its activites with this research and will make a substantial effort to measure net pollutant fluxes to the surface, under an expanded range of conditions, and to develop a parameterization of these fluxes as functions of atmospheric and generalized surface conditions. To measure these fluxes, DBER, in cooperation with EPA, is supporting the Argonne National Laboratory in utilizing the eddy flux technique at a number of locations with different surface characteristics. Recent field experiments suggest that under some conditions the deposition velocities (pollutant flux divided by near-surface concentration) of $\mathrm{SO}_{2}$ and sulfate can be almost the same, rather than different by a factor of 10 , usually assumed in the past (Weseley et al., 1977b).

Developed parameterizations, based on the eddy flux technique, will be compared with results from other field experiments in which losses to the surface are determined indirectly (e.g., urban plume studies). We will also continue model studies of the sensitivity of model results to representations of dry deposition.

\section{Task 8 - Pollutants and Precipitation}

To identify the mechanisms and rates governing the removal of $A E R$ pollutants by precipitation scavenging, and to determine the effects of $A E R$ pollutants on trace material balances and precipitation chemistry, specifically the acid-base relationships.

Although precipitation is episodic and its spatiality is highly variable, it is an important sink for atmospheric pollutants because of the effectiveness of the wet scavenging process. In addition, the relatively high levels of pollution in the Greater Northeast can have an important effect on the chemical balance of the precipitation.

The removal of atmospheric gases and particulate matter is extremely complex. Apparently, the removal rates depend on such parameters as particle size, pollutant concentration, precipitation type, droplet acidity, and interactions among them. Pollutant transformation can occur in water droplets; thus, processes taking place in clouds before precipitation occurs can affect what eventually reaches the ground. Falling rain can capture particles in the air below clouds, or it can evaporate, releasing transformed pollutants back into the air. Precipitation is discontinuous; thus, its effect on pollutant concentrations depends on where and when it occurs. Model sensitivity studies of this problem by Wendell et al. (1976) show substantially different patterns of deposition on the surface if rain is assumed to be continuous (as might happen in models attempting to calculate long-term average concentrations) rather than episodic.

The pollutant effects of inducing a significant perturbation in the chemistry of precipitation were first recognized as an important environmental problem in Scandinavia (e.g., see the review in Braekke, 1976). Although acidity is only one of many factors to consider, recent changes in precipitation acidity have been 
reported by Likens (1976) and Stensland (1977) in the United States and by Summers and Whelpdale (1976) in Canada. Substantial effects on aquatic ecosystems (e.g., in reducing fish populations in some lakes in New York State and around the Sudbury smelter in Canada) have also been observed (Likens, 1976; Beamish, 1976). Aquatic ecosystems can be particularly stressed during snowmelt conditions, when sulfate accumulated in the snow pack over extended winter periods is suddenly flushed into streams as the spring lifecycle begins [see Likens (1976) for a more detailed discussion]. Dramatic changes in the behavior of terrestrial ecosystems, as for example in the reproduction of some fern species (Evans and Bozzone, 1976), have been demonstrated in the laboratory with changes in precipitation acidity. Controlled exposure of plants to simulated rain with moderate acidity shows alterations in plant growth and productivity (e.g., see Lee and Weber, 1976), and similar effects are anticipated to occur in nature. Soil chemistry can also be affected. It has been suggested that the release of $\mathrm{N}_{2} \mathrm{O}$ to the atmosphere (and stratosphere) may increase as the $\mathrm{pH}$ of rain decreases. The identification of such impacts is one of the objectives of long-term ecological studies like those going on in the Hubbard Brook Experimental Forest (New Hampshire's White Mountains) and in the Walker Branch Watershed (Oak Ridge, Tennessee).

Understanding the precipitation pathways of pollutants in the atmosphere, including uptake, transformation, transport, and deposition mechanisms, is the objective of this MAP3S task. The planned research will build on a long history of activities (e.g., Changnon et al., 1971; METROMEX, 1974 and 1976), supported in part by DOE's predecessors (ERDA and AEC) that have addressed the scavenging of trace materials. It will be complemented by a program of observations, field experiments, and numerical modeling to obtain a better description of what is occurring, what mechanisms are producing the observed results, and how well these processes can be simulated. The observation program will use scales ranging from local to interstate. Also, MAP3S is helping ISWS to complete a data analysis for the multiyear METROMEX project, which (for DOE) looked at the scavenging of pollutants in precipitation and the resulting precipitation chemistry in the St. Louis area. The results will provide us with the knowledge to develop a plan for observing scales out to about $100 \mathrm{~km}$ east of Chicago. As part of the Chicago Area Program (CAP). MAP3S will be supporting the analysis of contaminants in precipitation, as a means to improve the understanding of pollutant mass balances downwind from the large Chicago metropolitan area.

MAP3S, in its research region, will support a high-quality prototype network for evaluating the chemical composition and properties of precipitation in the Greater Northeast, where "acid-rain" conditions are becoming more extensive. Unlike Scandinavia, a long-term record of precipitation quality, developed over a wide region, does not exist in the United States. The MAP3S network represents the first step in establishing a more complete, more extensive, and longer-term network, the need for which has been discussed by Cowling (1975) and is being initiated by the U.S. Department of Agriculture. As a prototype network, the MAP3S program will take special care to evaluate needed procedures, to compare collection techniques, and to investigate whether data collection should be eventbased as opposed to month-based or weekbased. This last aspcct may be very important, because light rains are indicated as having a lower $\mathrm{pH}$ than have heavier 
rains, a result which an event-basis measurement program could verify. Also, event basis sampling would allow the $\mathrm{pH}$ factor and other precipitation characteristics to be correlated with storm trajectories, permitting the source of precipitated pollutants to be analyzed. In addition, it would allow precipitation chemistry to be correlated with observed pollutant concentrations.

As of January 1, 1977, PNL had located samplers along a north-south line at four university-sponsored sites from upper New York State to Virginia. Plans for about four additional sites are being developed. This network, to be coordinated with air quality monitoring, will provide important information for use in comparing the pollutant concentrations in precipitation with the pollutant concentrations in the air. A list of species for which the precipitation samples are being analyzed is given in Table 2. The methodology for observing other sulfur oxides is being considered.

To simulate the effects of present emissions and the potentially increased future emissions, we require an understanding of the scavenging process of precipitation. MAP3S is therefore supporting a major field program, conducted by PNL and cooperating universities, to investigate the mechanisms by which precipitation scavenges pollutants from the atmosphere. Initially, the program will.focus on stationary storm systems, such as lake-effect storms, where aircraft measurements can be combined with a surface network in well-defined experiments. For example, it is anticipated that the Milwaukee urban plume, whose characteristics have been measured under fair weather conditions as part of Task 6, will intersect lake-effect storm systems. Such events will allow us to study how scavenging processes interact with pollutants of interest. Also, special tracers may be used to determine the microphysical mechanisms affecting pollutants.

In association with these observation and field studies, closely related numerical modeling studies are under way at PNL, ANL, BNL, and ISWS to develop an insight into the parameterization of the precipitation scavenging mechanism (the ISWS study is also being supported by non-DOE funding.) In addition, chemical transformation within raindrops is being numerically modeled at BNL. The objective of these studies is to develop the capability for predicting how changes in emission rates will affect precipitation quality.

Table 2

MEASUREMENTS TO BE MADE ON PRECIPITATION SAMPLES

Total acidity

Conductivity and $\mathrm{pH}\left(\mathrm{H}^{+}\right)$

$\mathrm{SO}_{4}^{=}, \mathrm{SO}_{3}^{=}$

$\mathrm{NO}_{3}^{-}, \mathrm{NO}_{2}^{-}$

$\mathrm{NH}_{4}^{+}, \mathrm{Na}^{+}, \mathrm{K}^{+}, \mathrm{Mg}^{++}, \mathrm{Ca}^{++}$

$\mathrm{PO}_{4}$

$\mathrm{F}^{-}, \mathrm{Cl}^{-}$

Dissolved Al 


\section{Task 9 - Weather and Climate Modification}

To determine the effects of $A E R$ pollutants on weather and climate, including effects on visibility, radiation transport, and on the amount and extent of precipitation.

An understanding of the effects of urban areas on local-scale precipitation and weather is beginning to emerge as a result of such projects as METROMEX. But the impact of pollutants on the week-to-week weather and its variations, and therefore possibly on the climate, over the regional and continental scales is very poorly understood, and most of the proposed climatic impacts remain speculative.

Visibility reduction is probably the most apparent pollutant effect, and evidence relating AER pollutants to such an effect (e.g., Waggoner et al., 1976) is growing. It has been suggested that injection of pollutants higher into the boundary layer by use of tall stacks has led to deeper layers of polluted, low-visibility air. In turn, the atmospheric residence time of pollutants is then extended, because elevated layers can be isolated by low-level nocturnal inversions. This lengthened opportunity for pollutants to be transported and transformed may contribute to visibility übstiuctioù over lärgc arcas.

Although visibility reduction can be an aesthetic and air safety problem, the impact of the aerosol on the atmospheric heating and cooling patterns may be a more serious problem. Changnon et al. (1975) and Bolin and Charlson (1976) suggest that the reduction in solar radiation reaching the surface, because of increased levels of tropospheric aerosols, may reduce the length of the growing season by several days to several weeks. In addition to total solar radiation changing, the ratio of diffuseto-direct radiation is changing (Wesely and Lipschutz, 1976), which may lead to biosystem responses. Whether the redistribution in solar energy absorption induced by aerosols leads to climatic effects remains uncertain.

The potential effects of increased atmospheric aerosols on the precipitation mechanism was considered at the Chemist/Meteorologist Workshop in 1975 (Slade et al., 1975). Because mechanisms are poorly understood, details are not clear. But the potential effects appear significant. Not only is precipitation chemistry affected, as discussed in Task 8 , but cloud processes (including coagulation, nucleation, cloud condensation nucleii formation, and other aerosol surface phenomena) can be altered, leading to suspected changes in precipitation patterns and amounts. Also, possible changes in dew frequency and fog formation, which in turn may catalyze various plant diseases, may occur.

These aerosol effects are potentially as significant as the more clearly defined human health and ecological effects. Unfortunately, neither adequate resources nor sufficient time are available for MAP3S to carry out more than the very limited activities described below, to start to develop baseline data. Thus, we will have to rely largely on research that may be sponsored by NSF and NOAA to give us the needed answers.

As a means of estimating the magnitude of the visibility (or turbidity) problem, MAP3S will support ANL in locating several silicon cell pyranometers (see Fig. 7) 


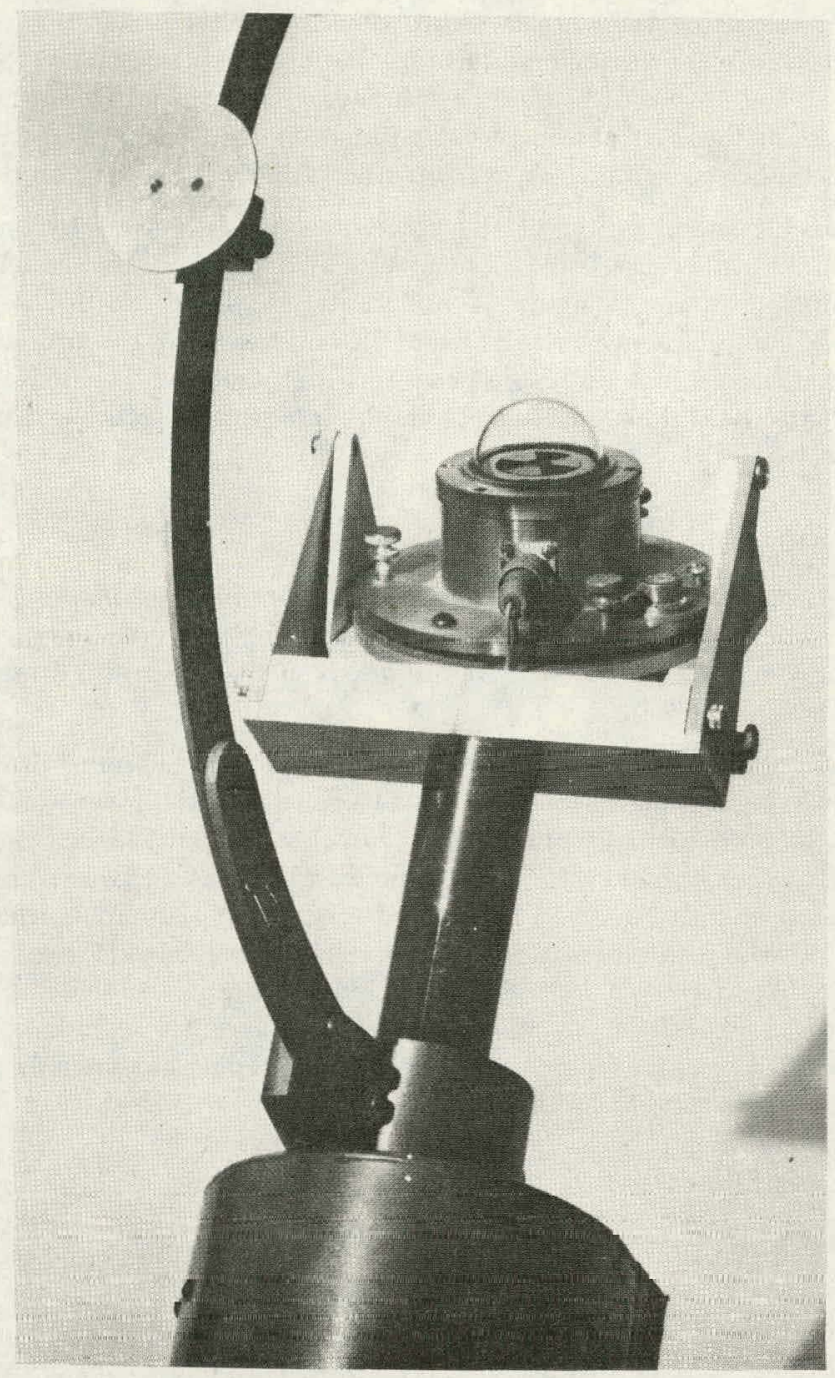

FIGURE 7-Pyranometer for measuring direct and diffuse solar radiation. MAP3S is establishing a network of such instruments to measure solar radiation throughout the Greater Northeast. Measurements will be used in studying the possible effects of increased aerosol concentrations on atmospheric turbidity, and in evaluating the potential for inadvertent weather modification (ANL photo).

in the Greater Northeast* for evaluating the effect of tropospheric aerosols on direct solar radiation (Weseley, 1975). Existing and planned networks are being

*As of May 15, 1977, pyranometers have been located in nonurban areas near St. Louis, Missouri; Manhattan, Kansas; Argonne National Laboratory, Illinois; Guelph, Ontario, Canada; Pellston, Michigan; State College, Pennsylvania; Charlottesville, Virginia; Oxford, Ohio; Knoxville, Tennessee; and Plattsburgh, New York. 
considered for siting the sensors. Also, objective criteria that suggest optimal locations to represent the regional turbidity pattern are being studied (Shannon et al., 1977). If high levels of turbidity are found, we will encourage further study of the changes in the distribution of solar radiation absorption, using appropriate numerical models developed as part of other atmospheric programs.

The possible modification of the precipitation mechanisms by an increased loading of atmospheric aerosol will be investigated as part of the modeling'studies on the precipitation scavenging of pollutants. However, we do not foresee a program as comprehensive as METROMEX being used for the entire region. We will attempt to recommend future programs that could address these questions, if preliminary indications point to potentially important effects.

\section{Task 10 - Numerical Modeling and Analysis}

To develop, verify, and demonstrate methods (numerical models) that will make it possible to accurately simulate the atmospheric transport and transformation of AER pollutants for use in assessing the various strategies for generating power.

The assimilation of the knowledge relating to the various processes and mechanisms controlling present air quality is essential, if we are to develop predictive methods (usually presented as numerical models) for use in simulating future air quality. Present data are interpreted almost exclusively with the use of models based on trajectory calculations and very simple pollutant conversion rates, e.g., $\mathrm{SO}_{2}$ to $\mathrm{SO}_{4}^{=}$. As represented in these Lagrangian models (e.g., see Heffter et al., 1975; Wendell et al., 1976; Sheih, 1977; Meyers et al., 1976; OECD, 1977), an air parcel is tracked from an emission region to a receptor region, or backwards from a polluted receptor region to a source. These models, as shown for example in Fig. 1, can be "tuned" (or adjusted) so that reasonable choices for various parameters result in reasonable agreement between model predictions and observed concentrations. Present grid models (e.g., see Hidy et al., 1976) attempt to represent all regional areas simultaneously. Because their meteorology is more complex than that of trajectory models, they usually resort to even more simplified representations of other processes. Note that in present models both the magnitude and distributions of the resulting concentrations can change dramatically, if such assumptions as those governing vertical mixing and the rates of sulfate formation and removal are altered. Diagnostic models for studying the altered emission patterns foreseen in future years will require accurate, theoretically sound parameterizations of the important physical and chemical processes.

Several of the attempted simplifications further illustrate the complexity of the simulation problem. For example, consider the calculation of long-term averages of pollutant concentration. An approach based on representing transport statistically by averaging trajectory paths over an extended period (Bolin and Persson, 1975 ), has been proposed as an alternative to representing them deterministically. This alternative approach, implemented by Sheih (1977) at ANL, appears to give reasonable results for monthly average concentrations, but it fails to represent episodic conditions. Wendell et al. (1976) have tested the assumption of using average precipitation rather than representing its episodic nature. They find significant differences in results for month-long average conditions. 
Topography has not been treated in model calculations of sulfate concentrations, yet the Appalachian Mountains bisect the Greater Northeast and surely influence pollutant concentrations. Also, vertical structure has been ignored almost totally. A simplified problem carried out by Kreitzberg (1976) shows that by looking at surface winds, for example, one is led to believe that pollution from the Ohio River Valley does not reach New York City, whereas elevated winds, followed by vertical mixing, could transport the pollution between these two areas.

As defined before, the goal of MAP3S is to develop an improved, verified, objective, quantitative capability to assess the impact, on air quality, of future changes in emission. Clearly, we can only meet this goal by notably improving our treatment of atmospheric phenomena in the representation of those phenomena by numerical models, and in coupling field experiments to model verification. In the light of the MAP3S goal and the projected multibillion dollar costs for equipment to control potential emissions (NRC, 1975), the effort required to improve this understanding by numerical model simulation is certainly justified.

In developing the MAP3S modeling subprogram, we will follow two approaches. One approach focuses on upgrading present Lagrangian models by improving some internal processes and adding others; also, it emphasizes a more extensive verification of model results against observed surface concentrations of emissions, especially in episodic conditions. During the development period, however, a model will always be available for application. Lagrangian models are suited to a wide variety of sensitivity studies, and we will capitalize on this feature. Also, if the chemistry of sulfur oxides can be represented with a linearized approximation, it may be possible to use such Lagrangian models to treat subregional areas in more detail and to utilize field data much faster than Eulerian grid models can utilize such data. Thus, MAP3S will support the acceleration of PNL's work with the Lagrangian model and the coupling of its trajectory calculations to BNL's objective windfield analysis model (described in Task 5). In addition, DOE-sponsored efforts at ARL to improve Lagrangian models will be followed closely.

The second approach concentrates on developing an Eulerian grid model that treats the geographical region as a number of fixed cells, each approximately $40 \mathrm{~km}$ on a side. Vertically, the model will be able to simulate the diurnal variation in depth of the surface mixed layer, surface and elevated emissions, topography, wind shear, detailed chemistry, and other factors that must be considered if multiday simulations are to be undertaken. These models will not be predictive, boundary layer models, although they may be interfaced with such models. Instead, they will be diagnostic models, relying on observed meteorological data to drive the transport, transformation, and deposition mechanisms. Research and development groups at ANL and BNL will each focus on parameterizing mechanisms that field programs at their laboratories are investigating.

An important aspect of model development is verification. Besides using specific field experiments to help develop detailed parameterizations of specific processes, we will compare integrated results from both the Eulerian and Lagrangian models with observations from the SURE network and MAP3S characterization flights. Comparisons will be made for both average and episodic conditions, to evaluate the model's capability in responding to the observed variability of observed concentrations. Also, MAP3S plans to carry out a few, very detailed, box budget 
experiments, to document the flux and fate of pollutants in a well-defined region. These experiments will also be simulated in the model to assess model accuracy.

As a final aspect of the modeling program, we plan to continue the application of models to various scenarios of future energy use. When we reach this stage of development, we expect to make the models generally available to researchers inside and outside the MAP3S program. We will coordinate our plans with the ASEV-sponsored NCUA, to develop questions for the models to investigate. Our modeling objective is to create a useful capability for formulating energy policy; thus, model applications will focus on such questions as the impact of dramatically increasing the use of coal in the Midwest, the effect of a widespread application of flue-gas desulfurization, the impact of emissions from the Ohio River basin as they affect the New York megalopolis, etc. Although we will develop point-source plume models to help interpret field experimental data, we will concentrate on models that deal with questions affecting regional or subregional energy policy, rather than questions affecting single plants.

\subsection{MAP3S MILESTONES}

The MAP3S research program combines the existing capabilities of DOE national laboratories, sponsored university groups, and contractor organizations. This combination will carry out the research needed to improve the scientific understanding on which an accurate assessment of AER pollutant effects depends. The 3 subprograms, divided into 10 tasks, provide a framework for achieving the goal of improving DOE's assessment capability. Approximate resource allocations, by task, are listed in Table 3 and detailed in Appendix B. Projected milestones by fiscal year for each task are given in Fig. 8 and they emphasize the foreseeable near term. An index to the description of accomplishments to date, included in the FY1977 Addendum, is given in Appendix C; an index to projects in the planning stage, also detailed in the FY-1977 Addendum, is given in Appendix D. 
Table 3

RESOURCE ALLOCATION BY TASK

\begin{tabular}{lcc}
\hline Task & $\begin{array}{c}\text { General } \\
\text { funding } \\
\text { level* }\end{array}$ Research groups \\
\hline
\end{tabular}

1. Quantify emissions from power production sources

L. BNL

2. Quantify emissions from nonpower production sources

L BNL

3. Characterize pollutant properties

M ANL, BNL, BYU, LBL, PNL

4. Determine pollutant distribution

H ANL, BNL, EML, PNL

5. Determine pollutant transport

H. ANL, ARL, BNL, EML, PNL

6. Identify transformation processes

H ANL, BNL, PNL, BYU, PNL

7. Determine mechanisms governing pollutant removal at the surface

M ÁNL, PNL

8. Identify mechanisms of pollutant scavenging by, and effect on, precipitation

$\mathrm{H}^{*}$. PNL, ANL; BNL, ISWS, university groups .

9. Determine pollutant effects on weather and climate

L' $A N L '$

10. Develop numerical modeling for assessment

H ANL, ARL, BNL, PNL

* Total activities, in thousands of dollars per year. $\mathrm{L}=\operatorname{low}(<\$ 100 \mathrm{k} / \mathrm{yr}) ; \mathrm{M}=\operatorname{medium}(\$ 100-\$ 300 \mathrm{k} / \mathrm{yr})$; $\mathrm{H}=\operatorname{high}(>\$ 300 \mathrm{k} / \mathrm{yr})$. 
Task 1

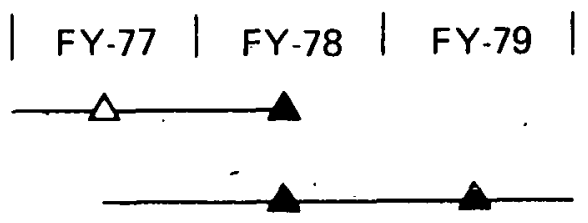

Task 2

Data compilation and updating Estimates of natural emissions

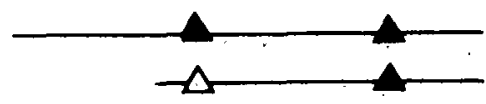

Task 3:

Special instruments located at field stations

Instrument research Instrument intercomparison Characterization of observed species

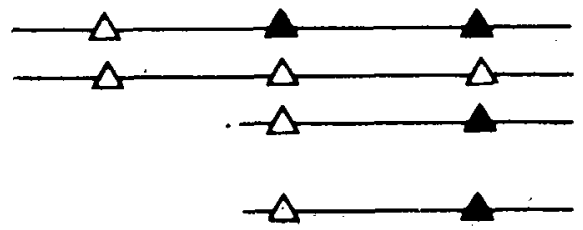

Task 4:

Aircraft sampling

Network quality assurance

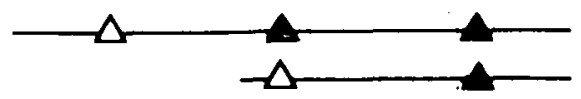

\section{Task 5}

Tracer technique development

Tracer experiments

Planetary boundary layer studies

Diaynustic wind fleld model

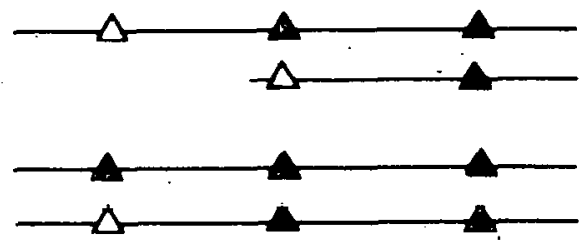

(a)

FIGURE 8-MAP3S project milestones ( $\triangle$ preliminary results available; $\triangle$ results available; — continuing research program). (a) Tasks 1-5. (b) Tasks 6-10. 
Task 6 :

${ }^{18} 0$ isotope studies

Point source plume

Urban source plume

Box budget studies

Plume chemistry modeling

\section{Task 7}

Dry deposition measurements in varied terrain

Task 8

Multistate precipitation chemistry network

METROMEX precipitation chemistry, data analysis

CAP precipitation chemistry studies

Precipitation scavenging experiments

Precipitation chemistry modeling

Task 9

Turbidity network

Task 10

Numerical methodology assessment

Trajectory model development

Eulerian grid model development

MAP3S data base
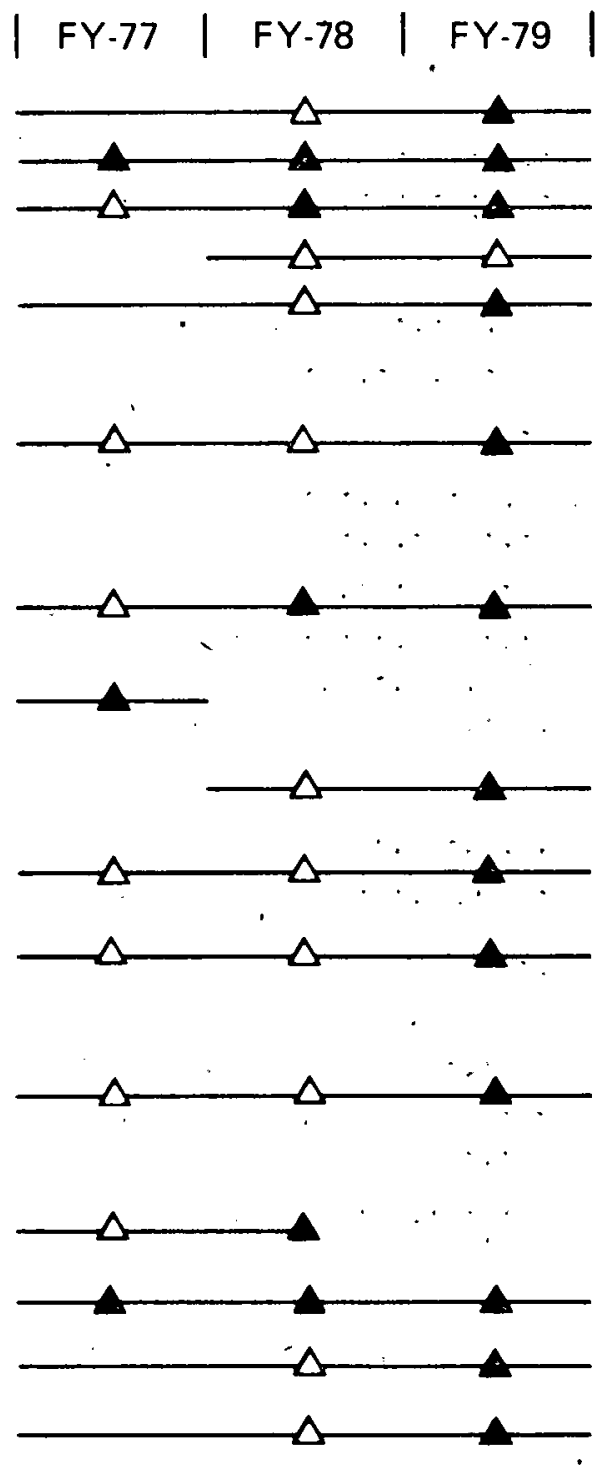

'(b)

FIGURE 8-Continued 


\section{THIS PAGE}

\section{WAS INTENTIONALLY}

LEFT BLANK 


\section{MAP3S PROGRAM MANAGEMENT}

Because the research needed to resolve the scientific uncertainties in the MAP3S program is substantial, the resources required to meet the research needs are also large. It will require the combined resources and talents of the three most active organizations (DOE, EPA, EPRI), acting with cooperation and coordination, to mount an efficient and effective national approach to resolve the scientific uncertainties.

As indicated previously in Table 1, MAP3S-supported research will emphasize:

- Field experiments, aimed at improving the understanding of atmospheric processes

- Numerical modeling, directed at simulating atmospheric processes

- Characterization of present air quality, using aircraft and surface measurements with substantial cooperation from the SURE program.

The MAP3S program will rely on the research of other programs and other agencies in several areas, to expand the results from DOE-supported projects and make them more comprehensive. The DOE effort is being directed by Dr. Michael C. MacCracken of the Lawrence Livermore Laboratory. As the Project Director, he is utilizing national laboratory and contractor staff to help oversee broad subdivisions of MAP3S research, as described more fully in Appendix E. MAP3S research is being conducted by several DOE national laboratories (ANL, BNL, EML, LBL, PNL) and other organizations (including ISWS, NOAA/ARL, and several university groups). The existing capabilities of these organizations, to conduct research that will yield a fundamental understanding of atmospheric processes, are being interfaced with the programmatic efforts on energy technologies to find answers to questions on a growing variety of national energy options.

In implementing the MAP3S program, we have started coordination with the EPRI and EPA programs on atmospheric sulfate and; in planning meetings, we have laid the foundation for joint activities. We have agreed to maintain project coordination, coordinate major field programs, exchange data, and hold joint scientific meetings.

In addition, an interface with DOE programs in human health and ecology, and with other agency programs in atmospheric sciences, has been established and will be encouraged.

To facilitate DOE's participation with these other agencies and between its own national laboratories, a data management center is being created at BNL. Processed data from MAP3S projects and information gathered by other programs will both be available at the center. 
We are distributing a quarterly newsletter* to provide information on the status of MAP3S activities and planning efforts. More detailed information on such elements as the precipitation chemistry network and the data base will be provided in specialized newsletters.

Scientific findings of the MAP3S program will be communicated through reports and publications. Major MAP3S reports will provide an up-to-date evaluation of the extent of scientific understanding relating to each task. Such evaluations will be used to develop priorities for future research.

-Initial issue, July 1976. Contact Dr. M. MacCracken, Lawrence Livermore Laboratory, Livermore, CA 94550.if you want your name added to the distribution list. 


\section{REFERENCES}

Alkezweenny, A. J., "The Growth of Aerosol in an Urban Plume," in Atmospheric Pollution, M. M. Benarie, Ed. (Elsevier Scientific Publishing Co., Amsterdam, 1976).

Alkezweeny, A. J., private communication (1977a).

Alkezweeny, A. J., " $\mathrm{SO}_{2}$ to Sulfate Conversion in Urban Plume," submitted to Geophys. Res. Letters (1977b).

Alkezweeny, A. J. and D. C. Powell, "Estimation of Transformation Rate of $\mathrm{SO}_{2}$ to $\mathrm{SO}_{4}$ from Atmospheric Concentration Data," Atmos. Environ., 11, 179 (1977).

'Altshuller, A. P., "Regional Transport and Transformation of Sulfur Dioxide to Sulfates in the U.S.,"J. Air Poll. Cont. Assoc., 26, 318 (1976).

Bachman, J. D., "Atmospheric Sulfates: An EPA Status Report," in Proc. 5th Annual Environ. Symp.: Environ., Law, and Sulfur Dioxide Update, Q97-105 (1976).

Beamish, R. J:, "Acidification of Lakes in Canada by Acid Precipitation and the Resulting Effects on Fishes," J. Water, Air, and Soil Poll., 6, 501 (1976).

Bolin, B. et al., Air Pollution Across National Boundaries. The Impact on the Environment of Sulfur in Air and Precipitation, Sweden's Case Study for the U.N. Conference on the Human Environment (Royal Ministry" of Foreign Affairs and Royal Ministry of Agriculture, Stockholm, 1971).

Bolin, B. and R. J. Charlson, "On the Role of the Tropospheric Sulfur Cycle in the Shortwave Radiative Climate of the Earth," Ambio, S(2), 47 (1976).

Bolin, B. and C. Persson, "Regional Dispersion and Deposition of Atmospheric Pollutants with Particular Application to 'Sulfur Pollution Over Western Europe," Tellus, 24, 281 (1975).

Braekke, F. H. (ed.), Impact of Acid Precipitation on Forest and Freshwater Ecosystems in Norway, Research Report June 1976, Agricultural Research Council of Norway (1976).

Breeding, R. J. et al., "Background Trace Gas Concentrations in the Central United States," J. Geophys. Res., 78, 7057 (1973).

Bremner, J. M., Sorption of Pollutant Gases by Soils, Iowa Stäte University Report C00-2530-7 (1976).

Brown, R. M. and R. W. Garber, "Airborne Measurements of Aerosol and Sulfate Concentration Discontinuities in Vertical and Horizontal Profiles," in Proc. 3rd Symp. Atmospheric Turbulence, Diffusion, and Air Quality, American Meteorological Society, Boston (1976): 
CEQ, Council on Environmental Quality, Environment and Conservation in Energy Research and Development, U.S. Government Printing Office, Washington, D.C. (040-000-00373-8) (1976).

Chamberlain, A. C., "Transport of Gases to and from Grass and Grass-Like Surfaces," Proc. Roy. Soc. A, 290, 236 (1966).

Chamberlain, A. C., "Transport of Gases to and from Surfaces with Bluff and Wave-Like Roughness Elements," Quart. J. Roy. Met. Soc., 94, 318 (1968).

Changnon, S. A., Jr., F. A. Huff, and R. G.-Semonin, "METROMEX: An Investigation of Inadvertent Weather Modification," Bull. Am. Met. Soc,, 52, 958 (1971).

Changnon, S. A., Jr. et al., "The Role of Aerosols in Producing Inadvertent Weather and Climate Modification," in Chemist/Meteorologist Workshop 1975 (Ft. Lauderdale, Florida), ERDA Report WASH 1217-55, Washington, D.C. (1975).

Changnon, S. A. and R. G. Semonin (eds.), Studies of Selected Precipitation Cases from METROMEX, Illinois State Water Survey, Urbana, Ill. (1975).

Coffin, D. L. and J. H. Knelson, "Acid Precipitation: Effects of Sulfur Dioxide and Sulfate Aerosol Particles on Human Health," Ambio, 5, 239 (1976).

Colucci, A. V., Sulfur Oxides: Current Status of Knowledge, Electric Power Research Institute, Palo Alto, Ca., Report EPRI EA-316 (1976).

Comar, C. L. and N. Nelson, "Health Effects of Fossil Fuel Combustion Products: Report of a Workshop," Environ. Health Perspectives, I2, 149 (1975).

Committee on Science and Technology, The Environmental Protection Agency's Research Program with Primary Emphasis on the Community Health and Environmental Surveillance System (CHESS): An Investigatory Report, U.S. Government Printing Office, Washington, D.C. (1976).

Cowan, G. A. et al., "Heavy Methanes as Atmospheric Tracers," Science, 191, 1048-1050 (1976).

Cowling, E. B., Statement to the House Subcommittee on the Environment and the Atmosphere, Hearings on Research and Development Related to Sulfates in the Atmosphere, July (1975).

Craig, N. L., A. B. Harker, and T. Novakov, “Determination of the Chemical States of Sulfur in Ambient Pollution Aerosols by X-Ray Photoelectron Spectroscopy," Atmos. Environ., 8, 15 (1974).

Cunningham, P. T. et al., Chemical Engineering Division Envtronmental Chemistry Annual Report, Argonne National Laboratory, Argonne, Ill., Report ANL 75.51 (1975).

Dana, M. T., J. M. Hales, and M. A. Wolf, "Rain Scavenging of $\mathrm{SO}_{2}$ and Sulfate from Power Plant Plumes," J. Geophys. Res., 80, 4119 (1975).

Davis, D. D., G. Smith, and G. Klauber. "Trace Gas Analysis of Power Plant Plumes Via Aircraft Measurement: $\mathrm{O}_{3}, \mathrm{SO}_{2}$, and $\mathrm{NO}_{x}$ Chemistry," Science, 186,733 (1974). 
Dyer, A. J. and B. B. Hicks, "Stratospheric Transport of Volcanic Dust Inferred from Solar Radiation Measurements," Nature, 208, 131 (1965).

Eatough, D. J., L. D. Hansen, R. M. Izatt, and N. F. Mangelson, "Analysis of Sulfite Species in Aerosols," presented at 173rd Natl. Meeting of Am. Chem. Soc., New Orleans (1977).

EPA, Health Consequences of Sulfur Oxides: A Report from CHESS, 1970-1971, Environmental Protection Agency, Research Triangle Park, NC, Report EPA-650/1-74-004 (1974).

EPA, Position Paper on Regulation of Atmospheric Sulfates, Environmental Protection Agency, Research Triangle Park, NC, Report EPA-405/2-75-007 (1975).

EPA, Air Program Strategy for Attainment and Maintenance of Ambient Air Quality Standards and Control of Other Pollutants, Environmental Protection Agency Report Draft, October 18 (1976).

EPA, Statement of Sulfates Research Approach, Environmental Protection Agency, Research Triangle Park, NC, Report EPA-600/8-77-004 (1977).

ERDA, Project Plan 1977-1979, National Coal Utilization Assessment, Division of Technology Overview, Environment \& Safety, Energy Research \& Development Administration, Washington, D.C., ERDA 77-19 (1977).

Evans, L. S. and D. M. Bozzone, "The Effect of Buffered Solutions and Sulfate on Vegetative and Sexual Development in Gametophytes of Pteridium Aquilinum," BNL Report 22100, submitted to Am. J. Botany (1976).

FISAPFE, Ist Int. Symp. Acid Precip. and the Forest Ecosystem, J. Water, Air, and Soil Poll., 6, Nos. 2, 3, and 4 (1976); 7, Nos: 3 and 4 (1977); 8, No. I (1977). (See also the workshop report on this meeting.)

Fisher, D. W., A. W. Gambell, G. E. Likens, and F. H. Bormann, "Atmospheric Contributions to Water Quality of Streams in the Hubbard Brook Experimental Forest, New Hampshire," Water Resour. Res., 4, 1115 (1968).

Forrest, J. and L. Newman, "Further Studies on the Oxidation of Sulfur Dioxide in Coal-Fired Power Plant Plumes," Atmos. Environ., 11, 465 (1977).

FPC, Federal Power Commission, Steam Electric Plant Air and Water Quality Control, Data for the Year Ended December 1, 1969, Based on FPC Form No. 67, Summary Report, FPC-S-229 (1969). Also, FPC-S-233 (1970), FPCS-239 (1971), and FPC-S-246 (1972).

Friend, J. B., "The Global Sulfur Cycie," in Chemistry of the Lower Atmosphere, S. I. Rasool, Ed. (Plenum Press, 1973), p. 177.

Garland, J. A., "The Dry Deposition of Sulfur Dioxide to Land and Water Surfaces," Proc. Roy. Soc. Lond. A., 354, 245 (1977).

Garratt, J. R. and B. B. Hicks, 'Momentum Heat and Water Vapor Transfer to and from Natural and Artificial Surfaces," Quart. J. Roy. Met. Soc., 99, 680 (1973).

Gartrell, F. E., F. W. Thomas, and S. B. Carpenter, "Atmospheric Oxidation of $\mathrm{SO}_{2}$ in Coal-Burning Power Plant Plumes," Am. Ind. Hyg. J., 24, 113 (1963). 
Gatz, D. F., "METROMEX: Air and Rain Chemistry Analysis," Bull. Am. Met. Soc:, 55, 92 (1974).

Georgii, H-W. et al., “Atmosphärische Spurenstoffe," Arbeitsbericht des SFB 73, Frankfurt a.M., Mains (1976).

Gifford, F. A., "Turbulent Diffusion-Typing Schemes: A Review," Nuclear Safety, 17, 68.(1976).

Granat, L., H. Rodhe, and R. O. Hallberg, "The Global Sulphur Cycle," Ecol. Bull. (Stockholm), 22, 89 (1976).

Hales, J.M., Tall Stacks and the Atmospheric Environment, EPA Project Report Draft (1976).

Hall, F. P., Jr., C. E. 'Duchon, L. G. Lee, and R. R. Hagan, "Long Range Transport of Air Pollution: A Case Study, August 1970," Mon. Wea. Rev., 101, 404 (1973).

Hansen,.L. D., L. Whiting, D. J. Eatough, T. E. Jensen, and R. M. Izatt, "Determination of Sulfur (IV) and Sulfate in Aerosols by Thermometric Methods," Anal. Chem., 48, 634 (1976).

Heffter, J. L., A. D. Taylor, and G. J. Ferber, A Regional-Continental Scale Transport, Diffusion, and Deposition Model, National Oceanic and Atmospheric Administration, Silver Spring, Md., Technical Memorandum ERL ARL-50, June (1975).

Hess, G. D. and B. B. Hicks, A Study of PBL Structure: The Sangamon Experiment of 1975, Argonne National Laboratory, Argonne, Ill., Report ANL 75-60, Part IV (1975).

Hicks, B. B. and P. S. Liss, "Transfer of $\mathrm{SO}_{2}$ and Other Reactive Gases Across the Air-Sea Interface," Tellus, 28, 348 (1976).

Hidy, G. M. et al., Characterization of Aerosols in California (ACHEX), Rockwell Science Center, Thousand Oaks, Ca., Final Report SC524.25FR (1974).

Hidy, G. M. et al., Design of the Sulfate Regional Experiment (SURE), Electric Power Research Institute, Palo Alto, Ca., Report EC-125 (1976).

Hindawi, I. J., J. A. Rea, and W. L. Griffis, "Response of Bush Beans Exposed to Acid Mist," presented at 70th Annual Meeting, Air Poll. Cont. Assoc., Toronto, Canada (1977).

Hitchcock, D. R., "Atmospheric Sulfates from Biological Sources," J. Air Poll. Cont. Assoc., 26, 210 (1976).

Holt, B. D., A. G. Engelkemeir, S. "A. Johnson, and P. T. Cunningham, "Oxygen Isotopy in the Formation of Sulfate Aerosols," pp. 683-692, in Proc. 2nd Int. Conf. on Stable Isotopes (Oak Brook, Ill., 1975), Report CONF-751027, ERDA (1976).

Holt, B. D., "Preparation of Carbon Dioxide from Sulfates, Sulfur Dioxide Air, and Water for Determination of Oxygen Isotope Ratio," Anal. Chem., 49, 1664 (1977). 
Husar, R. B., N. V. Gillani, J. D. Husar, C. C. Paley, and P. N. Turco, "LongRange Transport of Pollutants Observed Through Visibility Contour Maps, Weather Maps, and Trajectory Analysis," in Proc. 3rd Symp. Atmospheric Turbulence, Diffusion, and Air Quality, American Meteorological Society, Boston (1976a).

Husar, R. B. et al., "Pollutant Flow Rate Measurement in Large Plumes," presented at 171st Natl. Meeting of Am. Chem. Soc., New York (1976b).

ICEAP, Report from International Conference on the Effects of Acid Precipitation, Telemark, Norway, June (1976).

Jimeson, R. M., "Environmental Regulation - It's Not Nice to Fool the Power Plants," presented at ASME Symp.: Ambient Air Quality Standards - Here We Are, What Do We Do? (St. Louis, Mo.) pp. 101-128 (1975).

Junge, C. "The Cycle of Atmospheric Gases - Natural and Man-Made," Quart. $J$. Roy. Met. Soc., 98, 711 (1972).

Knox, J. B., T. V. Crawford, K. R. Peterson, and W. K. Crandall, Comparison of U.S. and USSR Methods of Calculating the Transport, Diffusion, and Deposition of Radioactivity, Lawrence Livermore Laboratory, Livermore, Ca., UCRL-51054 (1971).

Kreitzberg, C., private communication (1976).

Lee, J. J. and D. E. Weber, "A Study of the Effects of Acid Rain on Model Forest Ecosystems," presented at 69th Annual Meeting of Air Poll. Cont. Assoc., Portland, Oregon (1976).

Likens, G. E., "Acid Precipitation," Chem. and Eng. News, 29-44, November 22 (1976).

Likens, G. E. and F. H. Bormann, “Acid Rain: A Serious Regional Environmèntal Problem," Science, 184, 1176 (1974).

Lipfert, F. W., "The Association of Human Mortality with Air Pollution: A Review of Previous Studies," presented at the 70th Annual Meeting, Air, Poll. Cont. Assoc. (Toronto, Canada), Paper 77-44.1 (1977).

Marlow, W. H. and R. L. Tanner, "Diffusion Sampling Method for Ambient Aerosol Size Determination with Chemical Composition Determination," Anal. Chem., 48, 1999 (1976).

“METROMEX (Project METROMEX)," Bull. Am. Met. Soc., 55, 86 (1974).

"METROMEX Updàte," Bull. Am. Met. Suc., 57, 304 (1976).

Myers, R. E. and R. T. Cederwall, "Fossil Pollutant Transport Model Development," in The Brookhaven National Laboratory Regional Energy Studies Program, Annual Report for Fiscal Year 1975, P. F. Palmedo, Ed., Brookhaven National Laboratory, Upton, NY, BNL-50478 (1975).

Meyers, R. E., R. T. Cederwall, W. D. Ohmstede, and W. aufm Kampe, “Transport and Diffusion Using a Diagnostic Mesoscale Model Employing Mass and Total Energy Conservation Constraints," in Proc. 3rd Symp. Atmospheric Turbulence, Diffusion, and Air Quality, American Meteorological Society, Boston (1976). 
NEDS, National Emission Data System, Monitoring and Data Analysis Division, Environmental Protection Agency, Research Triangle Park, NC (1976).

NER, 1972 National Emission Report, Environmental Protection Agency, Research Triangle Park, NC, Report EPA-450/2-74-012 (1974).

Newman, L., J. Forrest, and B. Manowitz, "The Application of an Isotopic Ratio Technique to a Study of the Atmospheric Oxidation of Sulfur Dioxide in the Plume from a Coal-Fired Power Plant," Atmos. Environ., 9, 969 (1975).

NRC, National Research Council, Air Quality and Stationary Source Emission Control, prepared for the Committee on Public Works, U.S. Senate, Serial No. 94-4 (1975).

Nyberg, A., "On Transport of Sulphur Over the North Atlantic," submitted to Tellus (1976).

Odén, S., “The Acidity Problem - An Outline of Concepts," J. Water, Air, and Soil Poll., 6, 137 (1976).

OECD, The OECD Programme on Long Range Transport of Air Pollutants, Measurements and Findings, Organisation for Economic Cooperation and Development, Paris (1977).

OTA, Office of Technology Assessment, A Review of the U.S. Environmental Protection Agency Environmental Research Outlook, FY-1976 through 1980, OTA Report OTA-E-32 (1976).

Ottar, B., "Organization of Long Range Transport of Air Pollution Monitoring in Europe," J. Water, Air, and Soil Poll., 6, 219 (1976).

Prahm, L. P., U. Torp, and R. M. Stern, "Deposition and Transformation Rates of Sulphur Oxides During Atmospheric Transport Over the Atlantic," Tellus, 28, 355 (1976).

Ragaini, R. C. and J. M. Ondov, Trace-Element Emissions from Western U.S. Coal-Fired Power Plants, Lawrence Livermore Laboratory, Livermore, Ca., UCRL-77669 (1976).

Renne, D. S., Workshop Summary, Regional Studies Program Workshop on Air Quality and Meteorological Assessment, Battelle Pacific Northwest Laboratory, Richland, Wash., Report BNWL-2062 (1976).

Roberts, P. T. and S. K. Friedlander, "Photochemical Aerosol Formation, $\mathrm{SO}_{2}$, 1-Heptene, and $\mathrm{NO}_{\mathrm{x}}$ ' in Ambient Air," Environ. Sci. and Tech., 10, 573 (1976).

Robinson, G. D., "Absorption of Solar Radiation by Atmospheric Aerosols as Revealed by Measurements at the Ground," Arch. Met. Geophys. Bioklim., 12, 19 (196?).

Schwartz, S. E., private communication (1976).

Schwartz, S. E. and L. Newman, "Processes Limiting the Oxidation of Sulfur Dioxide in Stack Plumes," Environ. Sci. and Toch., in press (1977).

Semonin, R. G., "Tracer Chemical Experiments in Midwest Convective Clouds," in Proc. 3rd Conf. Weather Modif. (Rapid City, SD), pp. 83-87 (1972).

Semonin, R. G., "The Variability of $\mathrm{pH}$ in Convective Storms," J. Water, Air, and Soil Poll., 6, 395 (1976). 
Shannon, J. D., M. L. Wesely, and P. J. Brady, "Objective Sensor Placement for Sampling Regional Turbidity," submitted to Atmos. Environ. (1977).

Sheih, C. M., "Application of a Statistical Trajectory Model to the Simulation of Sulfur Pollution Over Northeastern United States," Atmos. Environ., 11, 173 (1977).

Slade, D. H., R. W. Beadle, and R. Newell, Chemist/Meteorologist Workshop 1975 (Ft. Lauderdale, Florida), ERDA Report WASH-1217-75, Washington, D.C. (1975).

Slinn, W. G. N., "Some Approximations for the Wet and Dry Removal of Particles and Gases from the Atmosphere," J. Water, Air, and Soil Poll., 7, 513 (1977).

Stensland, G. J., "Precipitation pH Decrease Since 1954 at Champaign-Urbana, lllinois," in Study of Air Pollution Scavenging. Fifteenth Progress Report, pp. 59-76, Illinois State Water Survey, Urbana, 11l. (1977).

Summers, P. W. and D. M. Whelpdale, "Acid Precipitation in Canada," J. Water. Air, and Soil Poll., 6, 477 (1976).

Tanner, R. L. and L. Newman, "The Analysis of Airborne Sulfate, A Critical Review," J. Air Poll. Cont. Assoc., 26, 737 (1976).

Tempelmeyer, K. E., "Snow, A Wintertime Sink for Sulfur Dioxide," in Proc. 4th Annual Environ. Eng. and Sci. Conf., Speed Scientific School, University of Louisville, Kentucky, March 4-5 (1974).

Volz, F. E., "Some Results of Turbidity Networks," Tellus, 21, 625 (1969).

Waggoner, A. P., A. J. Vanderpol, R. J. Charlson, S. Larsen, L. Granat, and C. Träjärdh, "Sulphate-light Scattering Ratio as an Index of the Role of Sulphur on Tröpospheric Oplics," Nature, 261, 120 (1976).

Wendell, L. L., D. C. Powell, and R. L. Drake, "A Regional Scale Model for Computing Deposition and Ground Level Air Concentration of $\mathrm{SO}_{2}$ and Sulfates from Elevated and Ground Sources," in Proc. 3rd Symp. Atmospheric Turbulence: Diffusion, and Air Quality, American Meteorological Society, Boston (1976).

Wesely, M. L., Measurements of Atmospheric Turbidity in an Arc Downwind of St. Louis, Argonne National Laboratory, Argonne, 1ll., Report 75-60 (1975).

Wesely, M. L. and B. B. Hicks, "A Review of Some Factors that Affect the Deposition Rates of Sulfur Dioxide and Similar Gases on Vegetation," J. Air Poll. Cont. Assoc., in press (19.77a).

Wesely, M. L., B. B. Hicks, W. P. Dannevik, S. Frisella, and R. B. Husar, "An Eddy Correlation Measurement of Particulate Deposition from the Atmosphere," Atmos. Environ., 11, 561 (1977b).

Wesely, M. L. and R. C. Lipschutz, "An Experimental Study of the Effects of Aerosols on Diffuse and Direct Solar Radiation Received During the Summer Near Chicago," Atmos. Environ., 10, 981. (1976).

Wexler, H., "The Great Smoke Pall, September 24-30, 1950," Weatherwise, 3, 129 (1950). 
White, W. H., J. A. Anderson, D. L. Blumenthal, R. B. Husar, N. V. Gillani, J. D. Husar, and W. E. Wilson, Jr., "Formation and Transport of Secondary Air Pollutants: Ozone and Aerosols in the St. Louis Urban Plume," Science, 194, 187 (1976).

Zak, B., "Long Distance Transport and Transformation Experiments Using a Lagrangian Measurement Platform," E®S. Trans. Am. Geophys. Union, 57, 924 (1976). 


\section{APPENDIX A}

\section{AGENCY AND PROGRAM ABBREVIATIONS}

AEC

AER

ANL

$A R L$

ASEV

BNL

BYU

CAP

DBER

DOE

EML

EPA

EPRI

ERDA

FEA

FPC

ISWS

LASL

LBL

I.I.I.

MAP3S
- Atomic Energy Commission

- Atmospheric Energy Related (pollutants)

- Argonne National Laboratory (Mr. B. Hicks, Dr. P. Cunningham*)

- (NOAA) Air Resources Laboratory (Dr. G. Ferber)

- Assistant Secretary for the Environment (DOE)

- Brookhaven National Laboratory (Dr. P. Michael)

- Brigham Young University (Prof. D. Eatough)

- Chicago Area Program (Mr. R. Semonin, ISWS)

- (DOE) Division of Biomedical and Environmental Research (Dr. D. Ballantine)

- Department of Energy

- Environmental Measurement Laboratory (Dr. P. Krey)

- Environmental Protection Agency (Dr. P. Altshuller)

- Electric Power Research Institute (Dr. R. Perhac)

- Energy Research and Development Administration (Mr. D. Slade)

- Federal Energy Administration

- Federal Power Commission

- Illinois State Water Survey (Mr. R. Semonin)

- Los Alamos Scientific Laboratory

- Lawrence Berkeley Laboratory (Dr. T. Novakov)

- Lawrence Livermore Laboratory (Dr. M. MacCracken)

- Multistate Atmospheric Power Production Pollution Study (Dr. M. MacCracken)

METROMEX - Metropolitan Meteorological Experiment (Mr. R. Semonin, ISWS)

MHD - Magnetó Hydrodynamics

MISTT - Midwest Interstate Sulfur Transport and Transformation Program (Dr. W. Wilson, EPA)

-Wherever possible, principal contacts arc given. 


$\begin{array}{ll}\text { NAAQS } & \text { - National Ambient Air Quality Standards } \\ \text { NASN } & \text { - National Air Surveillance Network (EPA) } \\ \text { NCUA } & \text { - National Coal Utilization Assessment (Dr. J. Hoover, ANL) } \\ \text { NEDS } & \text { - National Emission Data System (EPA) } \\ \text { NOAA } & \text { - National Oceanic and Atmospheric Administration } \\ \text { NRC } & \text { - National Research Council } \\ \text { NSF } & \text { - National Science Foundation } \\ \text { ORNL } & \text { - Oak Ridge National Laboratory (Dr. F. Harris) } \\ \text { PNL } & - \text { (Battelle) Pacific Northwest Laboratory (Dr. R. Drake, } \\ & \text { Dr. J. Hales) } \\ \text { RAPS } & - \text { Regional Air Pollution Study (Dr. P. Altshuller, EPA) } \\ \text { STATE } & - \text { Sulfur Transport And Transformation Experiment } \\ & \text { (Dr. W. Wilson, EPA) } \\ \text { 3URY } & - \text { Slalc Univirsity of New York (Prof. R. Faloonor) } \\ \text { SURE } & - \text { Sulfur Regional Experiment (Dr. G. Hidy, ERT) } \\ \text { WSU } & - \text { Washington State University (Prof. D. Adams). }\end{array}$




\section{APPENDIX B \\ MAP3S BUDGET}

The listing given below identifies MAP3S-funded activities as of February 1, 1977 , for FY-1977. Projects are given by title rather than by MAP3S project task, because a task breakdown cannot be precise (an approximate breakdown of total resources allocated to each task is given in Table 3 of the body of the report). Total funding listed for each project is not necessarily all devoted to the core program of MAP3S. Funding to ARL and EML is not listed, because it cannot be separated readily from the total budgets of these organizations (it is estimated to total $\$ 200 \mathrm{k}$ ). Funding proposed for FY-1978 in the President's budget to Congress is not listed, because such proposed funding is still subject to change.

\section{MAP3S Project Funding \\ (as of February 1, 1977)}

\section{NATIONAL LABORATORIES}

Argonne National. Laboratory:

MAP3S boundary layer investigations

Chemical characterization of aerosols

Oxygen isotope ratio studies of $\mathrm{SO}_{2}$ and sulfates

in the environment

Brookhaven National Laboratory:

Aircraft operations

Ambient aerosols

Atmospheric diagnostics

Data management

Modeling and analysis

Transport and transformation experiments

Lawrence Livermore Laboratory:

Project Director, program support

Pacific Northwest Laboratory:

Aerosol and trace-gas tránsformation 205

Aircraft operations $\quad 170$

MAP3S model studies $\quad 150$

Precipitation scavenging . . 475

Urban pollution and tracer studies . 50

\section{OTHER}

Brigham Young University

Illinois State Water Survey

State University of New York 
THIS PAGE

WAS INTENTIONALLY

LEFT BLANK 


\section{APPENDIX C MAP3S RESEARCH ACCOMPLISHMENTS}

Although the MAP3S program officially began on October 1, 1976, many of the research projects were either started in the previous fiscal year or were built on research programs of long standing. Research accomplishments to date are described in brief project reports, which are included in the FY-1977 Addendum to this report.* These reports, listed below, are categorized by MAP3S task.

\section{MAP3S Brief Project Reports in FY-1977 Addendum}

Task 1 - Power Production Emissions

1. Source Characterization (R. N. Dietz and S. E. Schwartz, BNL)

2. Emissions Inventory Compilation (C. M. Benkovitz, BNL)

Task 2 - Nonpower Production Emissions

1. Smelter Plumes, Sudbury (L. Newman and J. Forrest, BNL)

Task 3 - Pollutant Properties

1. Analytical Methods Development (R. L. Tanner, BNL)

2. Aerosol Measurement (W. H. Marlow, BNL)

3. Size Distributions of Airborne Elements (D. F. Gatz, ISWS)

4. Aerosol Source Identification: Factor Analysis of Elemental Composition Measurements (D. F. Gatz, ISWS)

Task 4 - Pollutant Distribution

1. MAP3S Experimental Sampling Network Design (C. M. Sheih and B. B. Hicks, ANL)

2. Objective Network Analysis (J. D. Shannon and M. L. Weseley, ANL)

3. Vertical Pollutant Distribution (R. W. Garber, R. M. Brown, and S. E. Schwartz, BNL)

4. Aircraft Operations (R. W. Garber, BNL)

Task 5 - Pollutant Transport

1. 1976 "Sangamoñ" PBL Profile Studies (B. B. Hicks, ANL)

2. Planetary Boundary Layer Acoustic Sounding Studies (E. L. Miller and B. B. Hicks, ANL)

3. Development of Long-Range Tracer System for Atmospheric Tracer Studies (G. J. Ferber, NOAA-ARL)

4. Measurement of Long-Range Tracer Compounds (R. N. Dietz, BNL)

5. Trace-Metal Concentration Ratios as Indicators of Pollution Source (J. A. Young, PNL)

\footnotetext{
-The reason for using an addendum is that we intend to keep the brief status reports updaied annually.
} 
Task 6 - Pollutant Transformation

1. Airborne Plume Study (R. W. Garber and L. Newman, BNL)

2. Theoretical Analysis of Chemical Reactions in Stack Plumes (S. E. Schwartz, BNL)

3. Long-Range Plume Transformation Study (A. J. Alkezweeny and J. M. Hales, PNI)

4. Milwaukee Urban Plume (R. L. Tanner, BNL)

5. Urban Plume Studies by Diffusion Sampling (R. L. Tanner and W. H. Marlow, BNL)

6. Numerical Modeling of Homogeneous, Gas Phase Kinetics of $\mathrm{NO}_{\mathrm{x}}, \mathrm{SO}_{2}$ and Hydrocarbons (R. F. Adamowicz, BNL)

Task 7 - Surface Removal Processes

1. Dry Deposition Studies (B. B. Hicks and M. L. Wesely, ANL)

Task 8 - Pollutants and Precipitation

1. MAP3S Precipitation Chemistry Network (M. T. Dana and J. M. Hales, PNL)

2. Precipitation Sampling (G. S. Rayuor, BNL)

3. METROMEX Network Chemistry Studies (R. G. Semonin, ISWS)

4. Study of the Precipitation $\mathrm{pH}$ in Illinois (G. J. Stensland, ISWS)

5. Chemical Tracer Scavenging Study (R. G. Semonin, ISWS)

6. Re-anàlysis of ANL Precipitation Scavenging Data (B. B. Hicks, ANL)

7. Precipitation Chemistry Modeling (R. F. Adamowicz, BNL)

8. Precipitation Scavenging (B. C. Scott and J. M. Hales, PNL)

Task 9 - Weather and Climate Modification

1. Turbidity Experimental Network (M. L. Wesely, ANL)

Task 10 - Numerical Modeling and Analysis

1. Development of Numerical Schemes (C. M. Sheih, ANL)

2. Model Development (D. C. Powell, L. L. Wendell, and W. E. Davis, PNL)

3. Model Testing and Application (L. L. Wendell, T. D. Fox, D. J. McNaughton, PNL)

4. Modeling of Long-Range Transport (J. L. Heffter, NOAA-ARL)

5. Application of a Lagrangian Statistical Trajectory Model (C. M. Sheih, ANL)

6. Regional 3-D Eulerian Diffusion-Advection Model with Nonlinear Chemical Reactions (R. E. Meyers, R. T. Cedcrwall, and J. Storch, BNL)

7. Support of Experimental Programs (L. L. Wendell and D. C. Powell, PNL)

8. Acquisition, Archiving, and Dissemination of Experimental Data Generated by MAP3S and Kelated Programs (C. Benkovitz, BNL) 


\section{APPENDIX D MAP3S RESEARCH PLANNING}

The MAP3S program will be supporting a great variety of research activities that are specifically aimed at reducing scientific uncertainty. Planned research activities for FY-1977, which are described in project planning statements in the FY-1977 Addendum to this report, are listed below under program tasks.

\section{MAP3S Planned Research Activities in FY-1977 Addendum}

Task 1 - Power Production Emissions

1. Source Characterization (R. N. Dietz, BNL)

2. Emissions Inventory Compilation (C. M. Benkovitz, BNL)

Task 2 - Nonpower Production Emissions

1. Nonenergy Related Point Source (L. Newman and J. Forrest, BNL)

Task 3 - Pollutant Properties

1. Development of Analytical Methods for Ground and Airborne Sampling (R. L. Tanner, BNL)

2. Development of Real-Time Instrumentation (R. L. Tanner, BNL)

3. Aerosol Measurement (W. H. Marlow, BNL)

4. Measurement of Sulfate, Acid Sulfate, and Nitrate Content of Atmospheric Aerosols ( $P$. Cunningham and $R$. Kumar, ANL)

5. Determination of Sulfur Speciation in Industrial Aerosols in an $\mathrm{SO}_{2}$-Rich Environment (D. J. Eatough, BYU)

Task 4 - Pollutant Distribution

1. Objective Sensor Placement (J. D. Shannon, ANL)

2. Vertical Pollutant Distribution Experiment (R. Garber, R. M. Brown, and P. Michael, BNL)

3. Size Discriminatory Chemical Analysis of Suboptical Particles (R. L. Tanner and W. H. Marlow, BNL)

4. Characterization Flights (R. W. Garber and R. M. Brown, BNL)

5. Quality Assurance of Analytical Results from the SURE Contractor

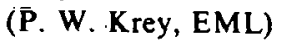

Task 5 - Pollutant Transport

1. Planetary Boundary Layer Studies (B. B. Hicks and T. Yamada, ANL)

2. AMBIENS Experiment (B. B. Hicks, ANL)

3. Development of Long-Range Tracer System (G. J. Ferber, ARL)

4. Measurement of Long-Range Tracer Compounds for New Atmospheric - Tracer Systems (R. N. Dietz, BNL) 


\section{Task 6 - Pollutant Transformation}

1. ${ }^{18} \mathrm{O}$ Enrichment of Atmospheric Sulfate, Sulfur Dioxide, and Water Vapor (P. Cunningham and R. Kumar, ANL)

2. Mechanics of Aerosol Particulate Interactions (W. H. Marlow, BNL)

3. Fundamental Studies of Aerosol Formation, Interaction, and Growth Processes (W. Marlow, BNL; J. Brock, Univ. Texas)

4. Airborne Plume-Studies (L. Newman and R. W. Garber, BNL)

5. Modeling Homogeneous and Heterogeneous $\mathrm{SO}_{2}$ Oxidation (S. E. Schwartz and S. Z. Levine, BNL)

6. Plume Transformation Study (A. J. Alkezweeny and J. M. Hales, PNL)

Task 7 - Surface Removal Processes

1. Dry Deposition Studies (B. B. Hicks and M. L. Wesely, ANL)

Task 8 - Wet Removal Processes

1. MAP3S Precipitation Chemistry Network (T. Dana, J. E. Rothert, D. W. Glover, and D. R. Drewes, PNL)

2. Precipitation Sampling (G. S. Raynor, DNL)

3. East-Central Illinois Precipitation Sampling Station (G. J. Stensland, State of Illinois, NSF)

4. Chicago Area Field Project (R. G. Semonin, ISWS)

5. Source Identification of AER Pollutants (D. F. Gatz, ISWS)

6. Agricultural Impacts of Wet/Dry Deposition (R. G. Semonin, ISWS)

7. Precipitation Scavenging (B. C. Scott and J. M. Hales, PNL)

Task 9 - Weather and Climate Modification

1. Turbidity Experimental Network (M. L. Wesely, ANL)

Task 10 - Numerical Modeling and Analysis

1. Model Development (D. C. Powell and L. L. Wendell, PNL)

2. Case Study Verification with Comprehensive Data Sets (L. L. Wendell, D. J. McNaughton, and D. C. Powell, PNL)

3. Gaussian Puff Model with Wind Shear (C. M. Sheih, ANL)

4. Trajectory Modeling of Long-Range Transport (J. L. Heffter, ARL)

5. Finite-Difference Diffusion Model (C. M. Sheih, J. D. Shannon, and T. Yamada, ANL)

6. Regional 3-D Eulerian Diffusion-Advection Model with Nonlinear Chemical Reactions (R. E. Mcycrs, R. T. Cederwall, and J. Storch, BNL)

7. Acquisition, Archiving, and Dissemination of Experimental Data Generated by MAP3S and Related Programs (C. Benkovitz, BNL) 


\section{APPENDIX E \\ MAP3S MANAGEMENT STRUCTURE}

The MAP3S program is led by Project Director Dr. Michael C. MacCracken, Lawrence Livermore Laboratory, who reports to Dr. David Ballantine, Environmental Programs, DBER, DOE. An interlaboratory participants advisory committee (ANL, BNL, and PNL representatives) advises the project director on interfacing the MAP3S program with laboratory resources and capabilities.

Responsibility for the scientific activities of the MAP3S research program is divided among three discipline-oriented working groups, one for each MAP3S subprogram (characterization, field experiments, numerical modeling and analysis). Leaders of the working groups are chosen from among project participants. A MAP3S scientific steering committee, consisting of 6 members ( 2 ranking members from each working group), advises the project director on scientific and administrative matters. Other project participants are often invited to take part in steering committee deliberations.

Each working group is inclusive rather than exclusive in its personnel make-up, i.e., all the institutions doing research in the particular task area are represented in the group. The groups are encouraged to meet as frequently as is necessary to exchange information, suggest and develop research plans, and carry out research activities. In addition, non-DOE researchers are invited to attend working group meetings, if they can be expected to participate in the discussions by broadening the base of experience and research or constructively assessing MAP3S activities. Also, working groups are encouraged to send out newsletters or use other means to foster an informed group membership.

The MAP3S management structure is shown schematically in the accompanying figure. Listed names are those of people who currently represent the working groups on the scientific steering committee. 


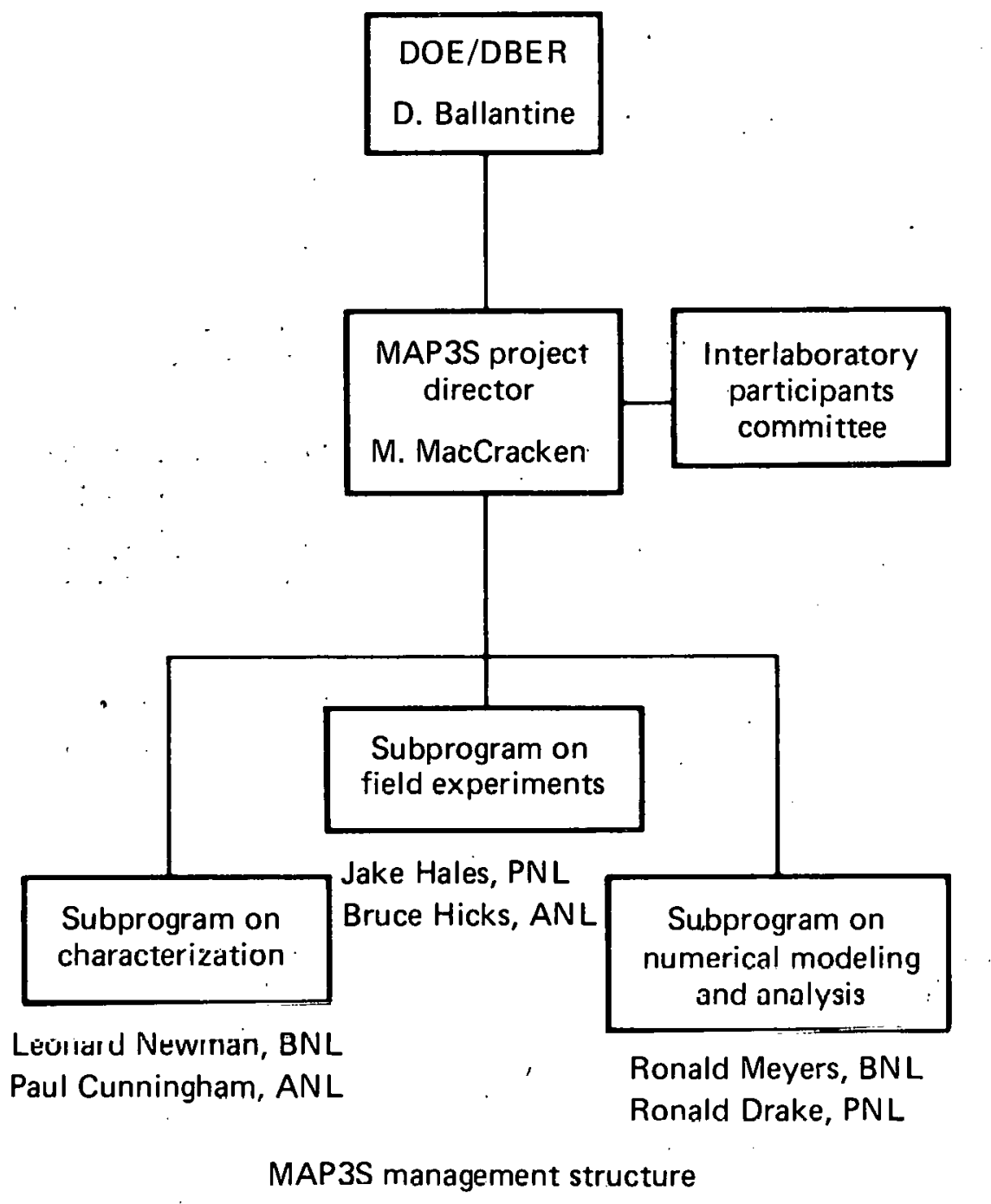




\section{APPENDIX F \\ DOE MAP3S-RELATED HEALTH-EFFECTS RESEARCH}

The high priority given to the MAP3S program is based on indications that emissions from power production may be playing a particularly important role in causing elevated particulate-sulfur concentrations. Preliminary evidence suggests that these concentrations then adversely affect human health, thus making the understanding of atmospheric processes a necessity if emissions are to be related to effects. Major research into health effects has been conducted by EPA and the National Institutes of Health. But the DOE/DBER program is expanding and we anticipate that our cooperation with this program will benefit both atmospheric research and health research.

DOE health-effects research on pollutants of interest to MAP3S is limited largely to toxicological studies. Other epidemiological and clinical research activities are largely related to occupational exposure that may induce such long-term, delayed effects as cancer. Most DBER research is now looking at chronic effects from low levels of pollution, in the belief that acute exposures are being adequately investigated by other programs and may soon be controlled. Major DOE-funded groups that are conducting respiratory toxicology and carcinogenesis studies are the Inhalation Toxicology Research Institute in Albuquerque, the Battelle Pacific Northwest Laboratory, the University of Rochester, the University of California/ Davis, and the Oak Ridge National Laboratory. The budget in health-effects research is nearly $\$ 3$ million for FY-1977.

To make sure that the MAP3S program addresses issues relevant to healtheffects research, we plan to:

1. Intercompare instruments used in measuring pollutants generated for toxicological testing and instruments used in measuring atmospheric pollutants, to ensure that the results are compatible.

2. Establish a dialogue between toxicologists and atmospheric chemists, to develop a priority list of pollutants to be measured in the atmosphere and tested on animals (i.e., to test pollutants most likely to be found in the atmosphere instead of testing pollutants that will not be found there).

3. Make atmospheric data on pollutant concentrations available, in a variety of formats, to allow the toxicological testing of, for example, occurrence frequency of various pollutant levels (i.e., to test if a dose of 10 units for 1 hour is the same as a dose of 2 unit for 10 hours).

Tables F-1 to F-5 identify the institutions carrying out major research programs in health effects, with interests relevant to MAP3S, as reported by DBER. 


\section{Source terms}

$\mathrm{SO}_{2}, \mathrm{NO}_{2}$, acid mists

Particulates: fly ash, simulated fly ash, acid sulfate particles

Mixtures of above

\section{Exposure}

Acute and chronic inhalation

\section{Biological studies}

Target tissues: trachea, bronchi, brónchioles, alveoli

\section{Evaluation}

Deposition, retention, distribution measurement

Nondestructive respiratory physiology

Inhibition of alyeolar macrophage clearance and immune function

Dose-effect definition for subacute and chronic respiratory diseases

Complete pathology (sacrificc and moribund)

\section{Table F-2}

HEALTH-EFFECTS RESEARCH AT BATTELLE PACIFIC NORTHWEST

\section{LABORATORY}

\section{Source terms}

$\mathrm{SO}_{x}, \mathrm{NO}_{x}, \mathrm{CO}$

Fly ash

Simulated mixed effluents around stack in a plume-trapping episode (ambient and 10x)

\section{Exposure.}

Inhalation

Repeated and chronic continuous

Above ambient

\section{Biological craluation}

Initial deposition and distribution kinetics

Nondestructive pulmonary physiology

Inhibition of pulmonary clearance

Progression of chronic pulmonary disease

Dose effect in señsitive and normal populations 


\section{Source terms}

$\mathrm{SO}_{2}$, acid mists

Particulates: fly ash, coal dust, and polycyclic aromatic hydrocarbons

\section{Exposure}

Acute, single and repeated

Inhalation and tracheal instillation

\section{Evaluation}

Physical-chemical characterization of aerosols

Inhibition of particle removal mechanisms

Modification of lung surface biochemistry

Basic theoretical modeling for lung deposition and clearance for insoluble and soluble particle associated chemicals

Validate models in experimental animals

\section{Table F-4}

\section{HEALTH-EFFECTS RESEARCH AT THE UNIVERSITY OF CALIFORNIA/ DAVIS}

\section{Source terms}

$\mathrm{SO}_{2}, \mathrm{NO}_{2}$

Particulates: soluble and insoluble sulfates, fine and ultrafine fly ash, inert silicate particles, inert silicate carrying identified trace and heavy metals

\section{Exposure}

Inhalation and trachea instillation

Single and repeated chronic

\section{Biological evaluation}

Comparative metabolism/distribution retention in rodents and monkeys.

Rapid screening for carcinogens in particle components and absorbed hydrocarbons

Nondestructive pulmonary physiology

Inhibition of pulmonary clearance and immune function of pulmonary macrophages

Alteration in pulmonary biochemistry 
Table F-5

HEALTH-EFFECTS RESEARCH AT OAK RIDGE NATIONÂL LABORATORY

\section{Source terms}

$\mathrm{SO}_{x}, \mathrm{NO}_{x}$, acid mists

Particulates: inert, fly ash (various coals), plus polycyclic aromatic hydrocarbons

\section{Exposures}

Inhalation and tracheal instillation

Controlled deposition in tracheal implants

Controlled exposure to tracheal cell cultures

\section{Biological evaluation}

Determine dose to cause cell transformation

Define dose to produce cancer in tracheal implant

Correlate above to animal in vivo dose to trachea and alveolar cells Measure reversible and irreversible staging to cancer production

Dose effect for carcinogenesis 


\section{APPENDIX G DOE MAP3S-RELATED ECOLOGY-EFFECTS RESEARCH}

Although the MAP3S program focuses on atmospheric implications of the increased use of fossil fuels, particularly coal, one of its prime interests is to provide data for use in assessing ecological consequences. As a result, we have stairted program coordination with the ecology research being carried out by DOE/DBER. We recognize that DOE is not the only agency pursuing ecological research. But a cooperative interaction by MAP3S with DBER can be readily accomplished and will produce atmospheric data that are suitable for meeting the particular needs of the ecological science community.

The ultimate objectives of DBER's pollution-effects research are:

- To be able to assess the type, severity, and extent (in space and time) of pollutant effects on biological systems (organisms, populations, and ecosystems)

- To determine the impact of such effects on overall environmental quality

- To develop a cost measure to assign to these effects.

These objectives can be met only with a knowledge of the dose-response relationships and the influence of other environmental factors on such relationships. The ability to assess the influence of pollutants on biological systems requires a network of basic atmospheric monitoring data, covering large regions and collected on a long-term basis.

Plants are the main environmental receptors of gaseous pollution and of acidified precipitation. The following issues are indicative of the factors that an atmospheric research program, such as MAP3S, must recognize in program planning:

- Plants respond to, and integrate in, a complex fashion when exposed to pollution events. Typically, these events are short lived. Therefore, any monitoring network must preserve data at the most frequent, feasible, measurement interval.

- Time averaging of pollutant data loses information essential for relating biological responses to exposure regimes. Plant processes may be affected by episodic fluctuations in pollutant concentrations, at intervals ranging from minutes to hours (e.g., response of photosynthesis).

- Plant responses to pollutants are influenced by a number of characteristics of the exposure kinetics: concentration, duration of event, frequency of event, rates of exposure (intensity), and time between events. All these characteristics influence plant responses to acid precipitation, and similar examples can be documented for gaseous pollutants. 
- Plant responses to pollutants created under controlled conditions in the laboratory must be demonstrated in the field. This is particularly important in the case of responses (synergistic or antagonistic) to pollutant combinations.

The problem of acidified precipitation is of particular concern at present. Apparently, the problem is regional in several industrial areas of the world. Acid precipitation is a form of chronic insult. But it can also constitute an acute perturbation in regions experiencing spring snowmelt. Acid precipitation, like gaseous pollutants, may cause long-term effects. The potential for exceeding the buffer capacity of lake or soil ecosystems, as well as the biological resiliency of organisms, populations, or communities, can lead to long-term effects. Initially, such effects may be subtle and manifest as a loss of vigor, predisposition to disease, or shifts in community composition and structure.

We are considering the following potential interactions of ecological studies with MAP3S:

1. Incorporation of a network of biological indicator stations within the MAP3S region (a similar network ic in operation near Pennsylvania State University).

2. Location of air monitoring sites near such intensely studied ecosystems as Hubbard Brook, New Hampshire, and Walker Branch, Tennessee.

3. Feedback between results of the precipitation chemistry sampling and results of controlled experiments on the effects of "acid" rain (including exposure time, frequency, etc.).

The institutions and general ecology-oriented scientific activities supported by DBER and relevant to the MAP3S research interests are listed below. During the MAP3S program, we will keep in contact with these groups.

\section{DBER-Supported Ecological-Effects Research Relating to MAP3S}

\section{Institution}

Argonne National Laboratory

Brookhaven National Laboratory

Oak Ridge National Laboratory

\section{Scientific Interest}

Effects of $\mathrm{SO}_{2}$ upon agricultural crops

Effects of acid rain on crop plants and fern' reproduction potential

Effects of acid rain on tree seedlings of the eastern deciduous forests 